\title{
Convective Heat Transfer in Rooms with Ceiling Slot Diffusers (RP-1416)
}

\author{
Kate Goldstein \\ Student Member ASHRAE
}

\author{
Atila Novoselac, PhD \\ Associate Member ASHRAE
}

Received February 25, 2010; accepted May 14, 2010

This paper is based on findings resulting from ASHRAE Research Project RP-1416.

\begin{abstract}
Convection at interior surfaces significantly affects the overall heat transfer in office buildings with large glazing areas. While a large number of these office buildings utilize ceiling slot diffusers at the glazed building perimeter, convection correlations specific to these diffusers have not yet been investigated. This paper describes convection correlations developed for ceiling slot diffusers and examines the effect of temperature, window geometry, and diffuser jet momentum on these correlations. The paper also examines the effect of venetian blinds on the overall correlations. The convective heat transfer coefficients are measured in both heating and cooling conditions. Overall, this paper represents the outcome of over 100 individual full-scale experiments. The results show that forced convection is dominant for a wide range of airflow rates. Correlations are developed as a function of the specific volumetric flow rate of supply air. The temperature of the supply air is also utilized as the reference temperature in convection calculations. The correlations are found to rely primarily on window position and the presence of blinds. The correlations are independent of the temperature difference between surface and supply, diffuser position, and diffuser jet momentum. The paper also quantifies the difference between the convection correlations developed for heated and cooled environments. Finally, utilizing energy modeling to quantify the difference between the new correlations and those previously used, it is found that former convection coefficients underestimate the energy demand. In the modeled building, utilizing the newly developed correlations for forced convection increased the peak cooling load by $24 \%$ and the overall energy consumption by $4 \%$ over the baseline that had natural convection with constant coefficients at window surfaces.
\end{abstract}

\section{INTRODUCTION}

Convective heat transfer at the interior surfaces of buildings accounts for a great proportion of the overall thermal load (Awbi 1998; Beausoleil-Morrison and Strachan 1999). Modeling programs rely on convective heat transfer correlations to quantify the magnitude of convection at each building surface. The correlation values vary widely among different programs and often presume natural convection to be the dominant mode of convective heat transfer. This can seriously underestimate the convective heat loss in mechanically ventilated buildings (Awbi and Hatton 2000). An incorrect assumption in the modeling of convection, such as inaccurate convection correlations, can translate into a large error in the overall estimation of total heat transfer within the building. In a study examining the significance of varied convective heat transfer coefficients, Lomas (1996) found that the cooling load could vary as much as $27 \%$. Considering the building energy consumption prediction, the degree of sensitivity of energy simulation to 
convection calculation models is approximately 8\% (Beausoleil-Morrison and Strachan 1999; Alamdari et al. 1984; Clarke 1991; Lomas 1996). Convection plays an important role in the accuracy of the overall heat transfer calculation. A good overall heat transfer model will link the accuracy of radiation and conduction models to the accuracy of the convection model. In energy modeling tools, indoor radiative heat transfer is usually described by precise radiation equations. The inaccuracy in radiation models comes from the neglect of participating objects within the room such as people, computers, and lights. Conduction is limited by the accuracy of one-dimensional homogeneous models used to represent multidimensional heat transfer occurring in nonhomogenous materials or building corners. Convection on the other hand is limited by the accuracy of the analytical or semiempirical correlation used for a characteristic space geometry and airflow distribution. This is the accuracy the new convection correlations seek to address.

There are significant differences in convective heat transfer not only between mechanically and naturally ventilated rooms, but also among different types of air distribution and heating and cooling systems such as: displacement ventilation, mixing ventilation with various ceiling and side wall diffusers, floor registers, radiant floor heating, and cooled ceiling panels (Novoselac et al. 2006a). Among these systems are ceiling slot diffusers, one of the most common airflow distribution systems in modern commercial buildings with large glass facades. With these systems, cold (or hot) air is supplied in the perimeter zones of buildings along the window surfaces to dissipate heat (or cover heat losses) at the source locations (Awbi 2003).

Ceiling slot diffusers in perimeter building zones are unique in their proximity to the window. This causes the vertical air supply jet to attach itself to adjacent surfaces. This phenomenon is termed the Coanda effect, and it transports the jet momentum along the window and wall surface. In addition to this forced convection, large temperature differences between supply air and window surfaces cause buoyancy. Depending on the direction of the surface heat flux (positive for summer or negative for winter), the surface-air temperature difference can generate a force that acts in the same or the opposite direction to the ceiling supply jet. Consequently, heat transfer at the window surfaces is potentially affected by both forced and natural convection. While at high volume flow rates one would expect the correlations to be dominated by forced convection, at lower flow rates, the large air temperature stratification could cause the effects of buoyancy to dominate. As mentioned before, the most commonly used convection correlations at window surfaces are based on the assumption that natural convection is the dominant mode of convective heat transfer. However, without knowledge of which effect dominates, it is difficult to know whether currently used models underestimate or overestimate convective heat transfer in commercial buildings with ceiling slot diffusers.

While specific correlations have been developed and utilized in energy analysis software for decades, there is currently a gap in the literature concerning forced air cooling and heating systems, including ceiling slot diffusers located near the window (Beausoleil-Morrison and Strachan 1999). As mentioned above, this is particularly important because this supply air configuration represents a large proportion of office ventilation systems. Furthermore, while numerous studies have been conducted to investigate heat transfer correlations in mixed convective regimes (Chen et al. 1989; Fisher 1995; Pavlovic 1991; Novoselac 2005), none of these studies focused on ceiling slot diffusers near the window surface, nor on the development of correlations specifically pertaining to the window.

Typical office buildings utilize not only ceiling slot diffusers close to the window, but also blinds which control the daylighting within the room and reduce the penetration of solar heat through the window. While the primary purpose of the blinds is to reduce heat gains from shortwave (solar) radiation, they also influence convective heat transfer as well as heat transfer in a room by long wave radiation. In addition, blinds affect the competition between natural and 

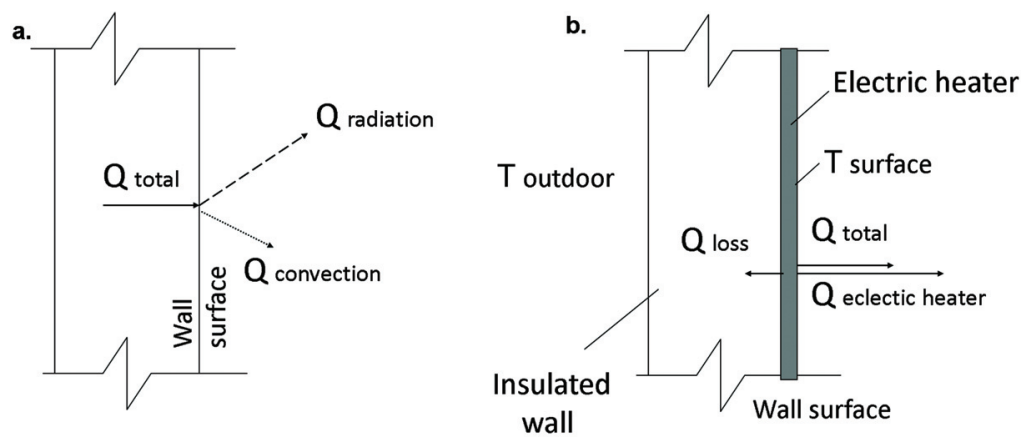

Figure 1. Heat transfer at (a) the wall-surface and (b) the wall with the electric heater.

forced convection and affect the solar heat gain and overall U-value of the window (Collins 2005). Oosthuizen (2008) and Collins et al. (2008) investigated the effect of blinds geometry on convective heat transfer for different configurations of blinds and windows. Wright et al. (2009) developed an empirical model that predicts total (convective and radiative) heat transfer from the interior of a window with a venetian blind. However, the model is primarily applicable for natural convection and does not include the effect of forced convection, which is particularly strong in the presence of ceiling slot diffusers.

The objective of the study described in this paper is to determine heat transfer correlations for internal surfaces within office buildings that utilize ceiling slot diffusers in perimeter building zones. Particular attention is paid to the large glazing areas typical in office buildings, and the effect of venetian blinds on the convection at window surfaces. Part of the challenge in modeling convection and developing accurate correlations for interior room surfaces lies in designing experiments that are representative of real buildings. To address this fact, the experiments were performed within a full-scale environmental chamber, utilizing ceiling slot diffusers near the window surface. In the following sections, this paper provides details about the general methodology for development of the convection correlations, describes the experimental setup and the experimental matrix, provides results in the form of correlations, and discusses the overall findings.

\section{METHODOLOGY}

The methodology section that follows has three parts: theoretical background, experimental facility setup, and experimental matrix. The experimental matrix will detail each phenomena studied, the cases for each, and its purpose within the larger framework.

\section{Theoretical Background}

The experimental methodology was based upon an energy balance at the wall surfaces of a full-scale environmental chamber. This procedure is similar to that used by Khalifa and Marshall (1990), Spitler et al. (1991a, 1991b), Awbi and Hatton (1999), and Novoselac et al. (2006a and 2006b). In each experiment, specific surface heat fluxes were produced at floor, sidewalls, window, and wall below window. The calculation of convective coefficients was then based on a surface energy balance, as illustrated in Figure 1.

The surface energy balance can be expressed as:

$$
Q_{\text {Convection }}=Q_{\text {Total }}-Q_{\text {Radiation }}
$$



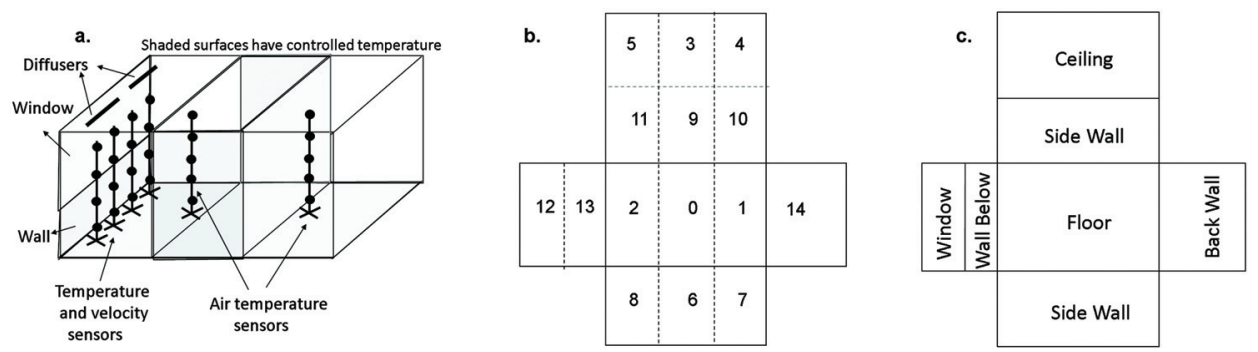

Figure 2. Test chamber diagram showing (a) the position of sensor stands, (b) unfolded characteristic surfaces, and (c) surface labeling.

where $Q_{\text {Total }}$ is the surface heat flux from the electric heaters or the hydronic cooling system less the conductive losses through the wall to the outside environment (Figure 1b):

$$
Q_{\text {Total }}=Q_{\text {Heater } / \text { Cooler Flux }}-Q_{\text {Loss }}
$$

Then the surface energy balance is:

$$
Q_{\text {Convection }}=Q_{\text {Heater } / \text { Cooler Flux }}-Q_{\text {Radiation }}-Q_{\text {Loss }}
$$

$Q_{\text {Loss }}$ depends on conductivity, surface area of the wall, thickness of the wall, and the difference between indoor and outdoor temperature. $Q_{\text {Heater/Cooler Flux }}$ is the heat flux originating from either the electric heating panels or the hydronic cooling system.

The surface balance (Equation 3) shows that to obtain the convective heat flux, radiative heat flux is needed. Radiative heat transfer between the interior walls of the chamber is governed by four factors: the areas of each surface $\left(A_{i}\right)$, the respective temperature differences between surfaces of the enclosure $\left(T_{i}\right.$ and $\left.T_{j}\right)$, surface emissivities $\left(\varepsilon_{i}\right)$, and the radiative heat exchange factor $\left(\Psi_{i, j}\right)$ between surfaces according to the following equation:

$$
Q_{i, j}=\varepsilon_{i} \psi_{i, j} A_{i} \sigma\left(T_{i}^{4}-T_{j}^{4}\right)
$$

Here, the radiative heat exchange factor $\Psi_{i, j}$ is defined as the fraction of radiation absorbed by surface $j$ that is emitted from surface $i$ including all radiation from surface $i$ towards other surfaces $(k)$, which is reflected towards surface $j$. The radiative heat exchange factor is calculated by solving the system of equations:

$$
\psi_{i, j}=\varepsilon_{j} F_{i, j}+\sum_{k=1}^{n} \psi_{k, j}\left(1-\varepsilon_{k}\right) F_{i, k} \quad i=1,2, \ldots, n \quad j=1,2, \ldots, n
$$

Then the sum $\Sigma Q_{i, j}$ (where $j=1,2, \ldots, n$ ) represents the total radiation to be exchanged by surface $i \quad\left(Q_{\text {radiation, } i}\right)$ due to radiation from all other surfaces in the enclosure. As the number of interacting surfaces increases and the multiple reflections between them get more complex, the radiation calculation becomes more computationally intensive. Furthermore, since the accuracy of the convection calculation relies on the precision of the radiation estimation, calculating radiation correctly is essential. As such, the walls of the room were divided into a larger number of characteristic surfaces (Figure 2), and the radiative heat exchange was calculated using 
the software previously developed for this purpose (Novoselac 2005). Inputs for this program were the averaged surface temperatures for each of the 15 characteristic surfaces (Figure 2b), and the total heat flux sent to each of these surfaces by electric heaters (Figure 1b).

The program calculates view factors based on surface areas and room geometry. It then calculates total radiative heat flux for each surface (Equation 4), determines convective heat flux based on Equation 3, and generates an output file quantifying convective, radiative, and conductive heat fluxes from each surface. Due to the heavy insulation of the test room, conductive heat fluxes were almost negligible compared to radiative and convective heat fluxes. Convection coefficients were then defined by using two reference temperature differences,

$$
h_{\text {supply }}=\frac{Q_{\text {Convection }}}{A_{\text {Surface }} \cdot \Delta T_{\text {Supply }}}
$$

or

$$
h_{\text {Room }}=\frac{Q_{\text {Convention }}}{A_{\text {Surface }} \cdot \Delta T_{\text {Room }}}
$$

where $\Delta T_{\text {Supply }}$ refers to $\left(T_{\text {Surface }}-T_{\text {Supply }}\right)$ and $\Delta T_{\text {Room }}$ refers to $\left(T_{\text {Surface }}-T_{\text {Room }}\right)$.

The choice of reference temperature, as either room temperature $\left(T_{\text {Room }}\right)$ or air supply temperature $\left(T_{\text {Supply }}\right)$, is dependent upon the dominant mode of convection within the room. If natural convection dominates, then room temperature is appropriate as a reference as long as the air is well mixed. However, as room air can be stratified due to the effect of buoyancy when natural convection dominates, the temperature must be taken at multiple points vertically from floor to ceiling, and averaged for an accurate reading. If the air temperature is significantly different near the room surfaces (not well mixed), a common and stable reference temperature is necessary, and the supply temperature should be used. A further question is whether to develop the correlations as a function of room volume flow rate or as a temperature difference between room surface and room temperature. The first case is more appropriate when forced convection dominates and the second when natural convection dominates. In their studies, Spitler et al. (1991a, 1991b) proposed the use of supply temperature as the reference temperature because it provides larger temperature differences between the surface and the air reference temperature, which enables the development of more accurate exponents and convection correlations. Spitler et al. also argue that developing the correlations as a function of air changes per hour (ACH) or volumetric flow rate $(\dot{V})$ is the most appropriate as it utilizes the room as the control volume rather than solely focusing on the surface boundary layer. Fisher and Pedersen (1997) and Novoselac et al. (2006a and 2006b) adopted this approach and developed the correlations for the room with various ceiling diffusers and displacement ventilation diffusers as a function of $\mathrm{ACH}$. The choice for both reference temperature and correlation development for the present study will be discussed at the end of this and the beginning of results section.

As most modeling programs base the convection coefficient on a surface to room air temperature difference, implementation of correlations based on supply temperature requires a conversion factor, which relates a new variable, $h_{\text {Equivalent }}$, to the $h_{\text {Supply }}$ developed in the correlation. Since the overall convective heat flux must be the same in both cases, $Q_{\text {Surface-Supply }}=$ $Q_{\text {Room-Surface }}$, then:

$$
h_{\text {Room }}=h_{\text {Supply }} \frac{\Delta T_{\text {Supply }}}{\Delta T_{\text {Room }}}
$$


As mentioned above, if natural convection dominates, the convective correlations will be developed as a function of the temperature difference between room surfaces and room air. Note that it is implicitly assumed that the room temperature is equal to the exhaust temperature when utilized as the reference. This is a standard assumption in most load calculations and energy simulation tools, and it is based on the assumption of high air mixing in the space.

For buoyancy driven vertical air flow, the convective heat transfer coefficient can be expressed as relationship between the Nusselt $(\mathrm{Nu})$ and Rayleigh $(\mathrm{Ra})$ numbers:

For laminar natural convection,

$$
\mathrm{Nu}=C_{1} \cdot \mathrm{Ra}^{1 / 4}
$$

And for turbulent natural convection,

$$
\mathrm{Nu}=C_{2} \cdot \mathrm{Ra}^{1 / 3}
$$

If forced convection dominates, the correlations are developed as a function of ACH or $\dot{V}$. For air, this can be seen with the use of the following relationship between Reynolds (Re) and Nusselt $(\mathrm{Nu})$ numbers (Bejan 2004):

For turbulent flow,

$$
\mathrm{Nu}=C_{3} \cdot \mathrm{Re}^{4 / 5}
$$

And for laminar flow,

$$
\mathrm{Nu}=C_{4} \cdot \mathrm{Re}^{1 / 2}
$$

The characteristic length in $\mathrm{Nu}$ and Re can be expressed by room volume: $V^{1 / 3}$ and Equations 11 and 12 transform to:

$$
\mathrm{Nu}=h \frac{V_{R o o m}^{1 / 3}}{k_{A i r}}
$$

and

$$
\mathrm{Re}=\frac{V_{\text {Supply }}}{v_{\text {Air }} V_{\text {Room }}^{1 / 3}}
$$

where $V_{\text {Room }}$ is the room volume, and $\dot{V}$ the volume flow rate.

For air, conductivity $\left(k_{A i r}\right)$, and dynamic viscosity $\left(v_{A i r}\right)$, are relatively constant for typical indoor temperature range, and the convection correlations 5 and 6 can be expressed as a function of $\mathrm{ACH}=\dot{V} / V$ :

$$
h_{\text {Forced }}=C_{5} \cdot \mathrm{ACH}^{m}
$$

The exponent $m$ depends on the type of flow. It is 0.8 for turbulent flow, 0.5 for laminar flow and between these two for transitional flow. If characteristic length does not have a large influence, $\mathrm{ACH}$ in Equation 15 can be replaced with $\dot{V}$ : 


$$
h_{\text {Forced }}=C_{6} \cdot \dot{V}^{m}
$$

Unlike previously developed correlations for the indoor environment (Spitler et al. 1991a, 1991b; Fisher and Pedersen 1997; Novoselac et al. 2006a, 2006b) correlations in this paper are not presented as a function of $\mathrm{ACH}$. This is because the perimeter zone, where slot diffusers are often used, has a variable depth within different buildings; a characteristic length defined as $V^{1 / 3}$ (incorporated into $\mathrm{ACH}$ ) can lead to misuses of these correlations. In enclosed, interior offices, the volume of the room is well defined and airflow generated by supply diffusers is confined by the enclosure. For this confined space, the cube root of the room volume $V^{1 / 3}$ can be used in Equation 14 as an appropriate length scale and $\mathrm{ACH}$ can be used within the forced convection correlation (Equation 15). When the office plan is open, as are most within the modern office buildings, the cube root of the volume is no longer an accurate length scale because the depth of the perimeter zone can vary. With an unconfined perimeter zone, only the windows and floor sections in and adjacent to external walls are directly affected by the jet from the supply diffuser. In cases like this, volumetric flow rate $(\dot{V})$ divided by length of the external wall $(L)$ is a more appropriate variable than $\mathrm{ACH}$ as it does not inherently contain any information about the perimeter room depth. Then the convection correlation for spaces of various sizes with common ceiling slot diffusers can be expressed as:

$$
h_{\text {Forced }}=C_{7} \cdot(\dot{V} / L)^{m}
$$

For the given room geometry the exponents of the correlations (exponents $m$ in Equation 15, 16, and 17) expressed as a function of either $\mathrm{ACH}, \dot{V}$, or $\dot{V} / L$ will be exactly the same while the coefficients $\left(C_{5}, C_{6}\right.$, and $\left.C_{7}\right)$ will be different for different geometries. Since the volumetric flow rate per unit of external wall $\dot{V} / L$ applies to all geometries, it is the correlation variable of choice in this paper and in all graphs.

\section{Experimental Setup}

An insulated and airtight chamber $\left(\mathrm{R}=5.3 \mathrm{~m}^{2} \mathrm{~K} / \mathrm{W}=30 \mathrm{~h} \cdot \mathrm{ft}^{2} \cdot{ }^{\circ} \mathrm{F} / \mathrm{Btu}\right)$ with dimensions of 5.5 $\times 4.5 \times 2.4 \mathrm{~m}^{3}\left(18 \times 15 \times 8 \mathrm{ft}^{3}\right)$ was used for correlation development. The internal surfaces were heated with electric heaters and cooled by hydronic cooling panels. Surface temperatures were measured by 54 thermostat sensors accurate to $\pm 0.1^{\circ} \mathrm{C}\left( \pm 0.18^{\circ} \mathrm{F}\right)$. An additional 10 thermistors were utilized to obtain the supply and return air temperatures as well as for the air temperature distribution in the central space of the room (Figure $2 \mathrm{a}$ ). A set of 16 resistance temperature detectors (RTDs) accurate to $\pm 0.2^{\circ} \mathrm{C}\left( \pm 0.36^{\circ} \mathrm{F}\right)$ measured the air temperature along the supply jet. The chamber was also equipped with 16 omnidirectional low-velocity anemometers with an accuracy of $\pm 0.02 \mathrm{~m} / \mathrm{s}( \pm 4 \mathrm{ft} / \mathrm{m})$ that measured velocity along the supply jet (Figure $2 \mathrm{a})$. Two flow stations accurate to $5 \%$ measured the flow rate into and out of the chamber. Two double slot diffusers, each $1.2 \mathrm{~m}$ (4 ft) long were set either $23 \mathrm{~cm}$ (9 in.) or $10 \mathrm{~cm}(4 \mathrm{in}$.) away from the window surface (Figure 2a). The distance between the two diffusers was $0.6 \mathrm{~m}(2 \mathrm{ft})$, and they were positioned as in Figure 2a. This setup is chosen based both on industry standards for office buildings with large glazing areas and on the ASHRAE space air diffusion design guidelines (ASHRAE 2009).

The chamber surfaces are divided into 14 characteristic surfaces (Figure $2 b$ ). This is done for two reasons. The first is to capture the temperature change at floor and sidewalls surfaces. For example, due to the placement of the diffuser, the air-surface temperature differential decreases as the supply air flows from the external wall towards the opposite wall. As such, the floor surfaces are divided from the front of the room to the back of the room to follow the flow of the diffuser 
moving in the direction perpendicular to the surface divisions. The second reason that the room is divided into these characteristic surfaces is to aid in the simulation of heated and nonheated surfaces. The floor of the room is heated to represent solar radiation coming in through the window and directed downward onto this surface. The sidewalls are heated to simulate the effects of internal heat sources that generate buoyancy in inner parts of the perimeter zone. These heaters serve to mimic the effects of internal thermal gains that occur naturally in office spaces due to people, computers, and other interior heat sources.

Each individual experiment was defined by three elements. The first was the room ventilation flow rate, which provided a certain volumetric flow rate into the test chamber. The second was the specific heat flux at each surface, and the third was the temperature differential between the supply air and room return temperature. The supply air temperature was defined by the overall heat flux such that the return temperature from the chamber was maintained at $24^{\circ} \mathrm{C}\left(75^{\circ} \mathrm{F}\right)$. The experiments began by adjusting surface heat fluxes, supply flow rate, and supply air temperature to the desired set point. Experiments were then run until the steady state condition in the chamber was reached, detected by the continuous monitoring of wall surface temperatures over a period of approximately 12 hours. When the steady state condition was obtained, jet velocity was measured and surface average temperatures were calculated based on numerous sensors positioned at each of the fifteen characteristic surfaces (Figure 2b). The characteristic surface temperatures were calculated as spatially averaged values from multiple sensors positioned at each surface. For each average temperature, the corresponding standard deviation was calculated to evaluate the uniformity of the surface temperature. These average temperatures were then used to calculate the radiative heat flux at each surface. The radiative heat flux was calculated by a program written in the C programming language (Novoselac 2005), which also calculated the convective heat flux values at each surface based on Equation 3. Also, for each convective heat flux, the program calculated both the standard deviation due to the temperature variation along characteristic surfaces and the uncertainty associated with the accuracy of the instruments utilized. Using the convective heat flux from each surface, the area of the surface, and the supply air and surface temperatures the value of $h$ was calculated for each surface by Equations 6 and 7.

\section{Uncertainty Analysis}

Convective heat flux is a function of the numerous measured variables including those associated with conduction and radiation. These variables include surface, supply and room temperatures, emissivity, conductivity, flow rate, and area. For the uncertainty analysis this can be represented in general form:

$$
Q=f\left(u_{1}, u_{2}, u_{3}, u_{4}, \ldots, u_{n}\right)
$$

where, when $Q$ represents convective heat flux, $u_{1}=T_{\text {Surface }}, u_{2}=T_{\text {Supply or Room Air }}, u_{3}=$ $Q_{\text {Electric Heater or Cooled Wall }}, u_{4}=T_{\text {Outdoor }}, u_{5}$ is surface emissivity $(\varepsilon), u_{6}$ is the area of the surface $\mathrm{A}, u_{7}$ is the chamber wall conductivity $(k)$, and $u_{8}$ is the thickness of the Wall 1 (Equations 2-7).

Using the general uncertainty analysis theory (ASHRAE 2000), the uncertainty associated in the measurement of convective heat flux may then be calculated using the following form,

$$
\delta Q=\sqrt{\left(\delta u_{1} \frac{\partial Q}{\partial u_{1}}\right)+\left(\delta u_{2} \frac{\partial Q}{\partial u_{2}}\right)+\left(\delta u_{3} \frac{\partial Q}{\partial u_{3}}\right)+\ldots+\left(\delta u_{n} \frac{\partial Q}{\partial u_{n}}\right)}
$$


The convection coefficient $(h)$ can be expressed as a function of $T_{\text {Surface }}, T_{\text {Supply }}$, and $Q_{\text {Convective }}$ (Equations 6 and 7). The uncertainty is then calculated in the same manner as in Equations 18 and 19.

The uncertainty of $Q_{\text {Convective }}$ depends on $Q_{\text {Heat Flux }}, Q_{\text {Radiation, }}$ and $Q_{\text {Loss }}$. For correlation development in the cooling regime with electric heating a power meter accurate to $3 \%$ of the measured value was used. For correlation development in the heating regime the uncertainty depended primarily upon the uncertainty of the supply and return temperature of water in the cooling panels, $\pm 0.1{ }^{\circ} \mathrm{C}\left( \pm 0.18^{\circ} \mathrm{F}\right)$. It was less dependent on the uncertainty of the water flow meter, which was accurate to $2 \%$ of the measured value. For the calculation of conductive losses through the wall ( $\left.Q_{\text {Losses }}\right)$ an electric power meter was used, ITI GHT-1C-(210), calibrated to an accuracy of $1 \%$ of the measured value. The impact of the accuracy of conductive losses was also included in the uncertainty analysis, but because losses were very small, any inaccuracy in the measurement of $Q_{\text {Loss }}$ contributed little to the overall accuracy of $Q_{\text {Convective }}$.

The largest uncertainty in the calculation of $Q_{\text {Convective }}$ came from the measurement of radiative heat flux where the major uncertainty came from two elements. The first is the measurement of wall surface temperatures and the second is the emissivity of the chamber walls. This was not due to the temperature sensor accuracy, but to the sensitivity of radiation calculations to small temperature differences between surfaces. The uncertainty analysis (Equations 18 and 19) was applied for Equations 4 and 5 and, due to the complexity of the equations; the uncertainty calculation is integrated into the radiation calculation software. The accuracy of chamber dimensions is high and thus not included in uncertainty analysis.

The uncertainty calculation for $h$ was based on Equation 6 or 7. The convective coefficient, $h$, is dependent upon the convective heat flux from the surface and the temperature difference between either, 1) surface and room or, 2) surface and supply air. The absolute accuracy of the temperature difference $\delta T$ is a function of the temperature sensor accuracy and derived by Equation 19.

Overall the largest uncertainty in the calculation of $h$ came from the measurement of temperatures used within the calculation of radiation and the measurement of the heat flux from the cooling panels, when used. In these cases, a large effort was dedicated to securing the precise measurement of air and room surface temperatures and, for cooling panes, water supply and return temperatures. The precision of the air volume flow rate $(\dot{V})$ measurement did not affect the accuracy of the convection heat transfer coefficient, $h$, but did have an effect on the accuracy of the overall convection correlation when developed as a function of a specific flow rate: $h=f(\dot{V} / L)$. The flow rate $(\dot{V})$ was measured with a flow meter with an accuracy of $5 \%$.

\section{Experimental Matrix}

Table 1 shows the experimental matrix with studied phenomena, number of cases for each phenomena, and a short description of studied cases. The total number of cases was 23 and for each case four or five experiments (each at a different flow rate) were conducted as described in the methodology section. The supply airflow rates provided a range of specific flow rates $(\dot{V} / L)$ from 25 to $130 \mathrm{~m}^{3} / \mathrm{h} \cdot \mathrm{m}$ (from 4.5 to $23.3 \mathrm{cfm} / \mathrm{ft}$ ), which corresponded to 1.5 to 10 ach in the test chamber. Convection correlations were calculated for window surface, wall below the window, and floor for each individual case where the experiments represented the points for correlation development.

The phenomena chosen to be studied and presented in Table 1 were based on initial trials and were modified based on their results. The experimentation phase began with the belief that the difference in temperature between surface and supply would have the greatest impact on the convective heat transfer. When it was found that this was not the case, experimentation moved on to study the momentum of the jet, with the belief that this would have a great influence on the 
(c) 2010 American Society of Heating, Refrigerating and Air-Conditioning Engineers, Inc. (www.ashrae.org). in either print or digital form is not permitted without ASHRAE's prior written permission.

Table 1. Experimental Matrix

\begin{tabular}{lcc}
\hline \multicolumn{1}{c}{ Studied Phenomena Description } & $\begin{array}{c}\text { \# of } \\
\text { Cases }\end{array}$ & Case Condition Description \\
\hline \hline 1. Effect of supply temperature & 3 & Small, medium, large surface-supply $\Delta T$ \\
2. Effect of diffuser position & 2 & $10 \mathrm{~cm}$ and $23 \mathrm{~cm}$ (4 in. and 9 in.) diffuser position \\
3. Effect of momentum & 3 & Single slot, double slot, and central diffuser \\
4. Effect of window size & 2 & Window as full wall and half the wall \\
5. Effect of window position & 2 & Half window located on top half, bottom half \\
6. Effect of window sill & 2 & Extruded sill (whole bottom wall), lip sill \\
7. Effect of open blinds & 2 & Open Blinds for both full and half window \\
8. Effect of temperature on cool wall & 3 & Small, medium, large surface-supply $\Delta T$ \\
9. Effect of cooling wall & 2 & Heating (cooled wall), cooling (heated wall) \\
10. Effect of central diffuser & 2 & Diffuser positioned 1.5 m (5 ft) from window \\
\hline
\end{tabular}

convection. It was found that this was also not a determining factor. As such, experimentation moved to the study of geometrical configurations including the size and placement of the window and diffuser jets. It was found that the size and placement of the window had the largest influence on the convective heat transfer of the geometry studied. The choice of phenomena to examine when blinds were included was based on what had been learned from experiments without blinds. Since it was found that the jet attaches itself to the surface even at low flow rates, it was important to identify whether these correlations could be used when the Coanda effect did not play a role, or when the buoyancy of the jet acts in the opposite direction, serving to effectively hinder rather than help the convective heat transfer. As such, experimentation moved to the heating condition with the diffuser placed one foot away from the window surface.

The overall purpose of the studies listed in Table 1 was to examine the relative effects of forced and natural convection and to quantify the influence of diffuser position, window size, window position, jet momentum, windowsill geometry, and venetian blinds. For analyzed cases experiments were conducted for different flow rates that provided flow 25, 45, 65, 98, and 130 $\mathrm{m}^{3} / \mathrm{h}$ per meter of external wall $(4.5,8.1,11.7,17.6$, and $23.3 \mathrm{cfm}$ per foot of external wall), corresponding to $1.5,3.5,5,7.5$, and 10 ach in the test room. In all cases, results were referenced back to the base case for correlation comparison (Phenomena 1-Case 1: large temperature difference for the cases with no blinds; Phenomena 7-Case 1: large temperature difference for the cases with blinds).

The first phenomenon studied in the chamber had the most basic setup: an office with double slot ceiling diffusers placed $23 \mathrm{~cm}$ (9 in.) from the window operating from 1.5 to 10 ach. In the three cases where effect of supply temperature was analyzed the three different temperature differences between supply and room air were small $\left(5.2^{\circ} \mathrm{C}, 9.4^{\circ} \mathrm{F}\right)$, medium $\left(8.3^{\circ} \mathrm{C}, 14.9^{\circ} \mathrm{F}\right)$, and large $\left(11.8^{\circ} \mathrm{C}, 21.2^{\circ} \mathrm{F}\right)$. This generated corresponding temperature differences between supply air and window surface of $7.0^{\circ} \mathrm{C}, 10.9^{\circ} \mathrm{C}$, and $15.7^{\circ} \mathrm{C}\left(12.6^{\circ} \mathrm{F}\right.$, $19.6^{\circ} \mathrm{F}$, and $28.3^{\circ} \mathrm{F}$ ). These temperature differences were taken from the values of each experiment at 9 ach. 
The studied Phenomena 2 in Table 1 analyzed the effect of diffuser distance from the window by placing the diffuser at 10 and $23 \mathrm{~cm}$ ( 4 in. and 9 in.) from the window surface. The next phenomenon studied was the effect of the diffuser velocity. One slot of the diffuser was blocked subsequently doubling the velocity of the jet stream. The fourth and fifth studies looked at the ratio of heat fluxes between the simulated window and wall below the window. The fourth effectively glazed the entire back wall while the fifth shifted the window to the lower portion of the wall. The sixth phenomena added a windowsill to the model. The sixth placed only a small sill between the window and wall surfaces while the seventh added a thick insulated wall layer on the lower half of the wall.

The next studied phenomenon (Phenomenon 7 in Table 1) is related to the effect of the blinds. The experimental setup is equivalent to the first phenomenon studied but with the inclusion of blinds, investigating the effect of the temperature difference between the room and supply air of the heating ventilating and air-conditioning (HVAC) system. This phenomenon also looked at the effect of the length of blinds, testing blinds covering both half of the window and the full window. The next phenomenon (Phenomenon 8 in Table 1) studied heating with slot diffusers. For these experiments, the electric heating elements were switched off, and the effect of the cool window surface was produced by means of a hydronic cooling system. These experiments served to investigate the effect of temperature difference in the heating condition. In the ninth phenomenon studied, the heating and cooling conditions were compared for the same setup in the absence of internal heat sources. To study this phenomenon the complete back wall was heated by the hydronic system and then cooled with supply air, and subsequently cooled by the hydronic system and heated with hot supply air. Finally, in the last phenomena studied, the effect of placing the diffuser at a greater distance from the wall surface was studied. For this investigation, the diffuser was positioned $23 \mathrm{~cm}$ and $1.5 \mathrm{~m}$ (9 in. and $5 \mathrm{ft}$ ) from the window with the intent to investigate the impact of the diffuser on convection at windows when the diffusers are positioned far enough from the wall to prohibit amplification by the Coanda effect.

\section{RESULTS}

In the following section, the determination of the appropriate reference temperature will be discussed. Next, the results from each of the phenomena listed in Table 1 will be presented. This will be followed by a brief analysis of the results. The subsequent section will focus on overall synthesis and implications of these results.

\section{Forced vs. Natural Convection}

The results are presented with the temperature of room supply as the reference and Figure 3 illustrates the first reason for this choice. With a ceiling slot diffuser, the air in the room is gradated; at the diffuser, air at approximately $13^{\circ} \mathrm{C}\left(55^{\circ} \mathrm{F}\right)$ enters the room and washes the window. By the time this air reaches the floor it has warmed considerably, and gets warmer as it circulates throughout the room. The room temperature sensors read the air toward the middle and back of the room where the air temperature is most steady, but significantly warmer $\left(25^{\circ} \mathrm{C}\right.$, $77^{\circ} \mathrm{F}$ ) than the air stream at the window. Another way to think of this is that due to the jet attaching to the window surface, the external window is essentially isolated from the rest of the space. As such, the supply is a more appropriate reference temperature as this temperature governs the behavior of the overall window surface convection (See Equations 6 and 7 for the final form of the convection coefficient relationship).

The second reason for the use of supply temperature as the reference is the increased accuracy of the developed correlations as previously shown by Spitler et al. (1991a and 1991b). In some cases, the use of room temperature as the reference causes very small values for the temperature difference, which increases the uncertainty (Equations 18 and 19). Figure 4 shows that when the 
(c) 2010 American Society of Heating, Refrigerating and Air-Conditioning Engineers, Inc. (www.ashrae.org).

esearch (Vol. 16, Issue 5, September 2010). For personal use only. Additional reproduction, distribution, or transmission in either print or digital form is not permitted without ASHRAE's prior written permission.

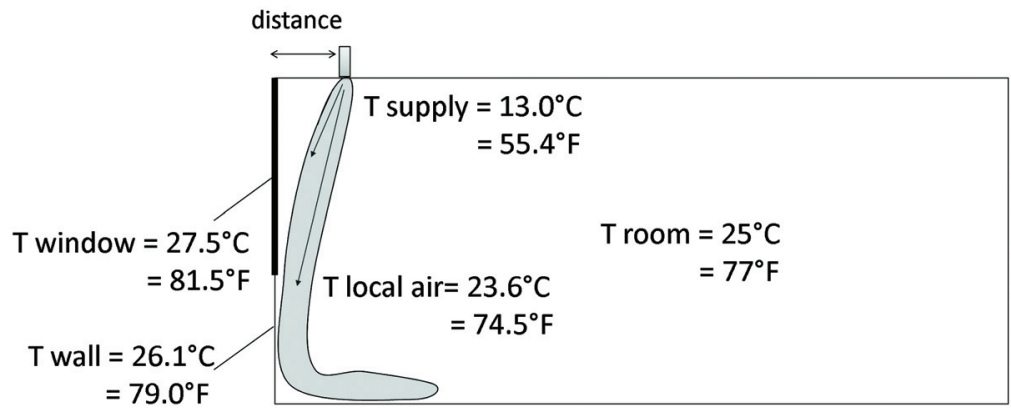

Figure 3. Room temperature air stratification.

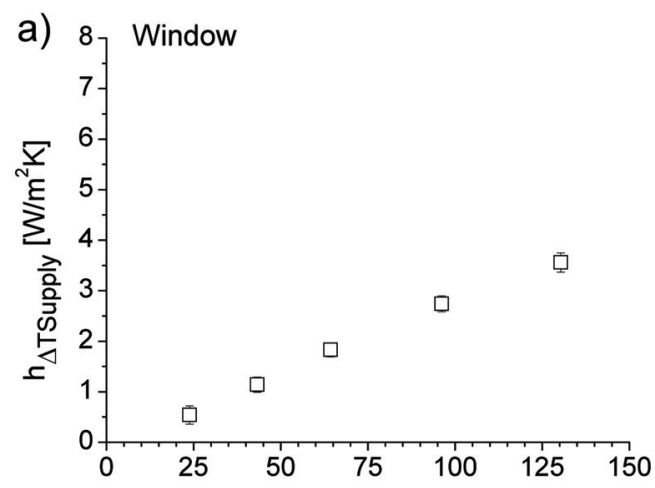

Flow Rate per Wall Length: V/L $\left.\left[\mathrm{m}^{3} / \mathrm{h} / \mathrm{m}\right)\right]$

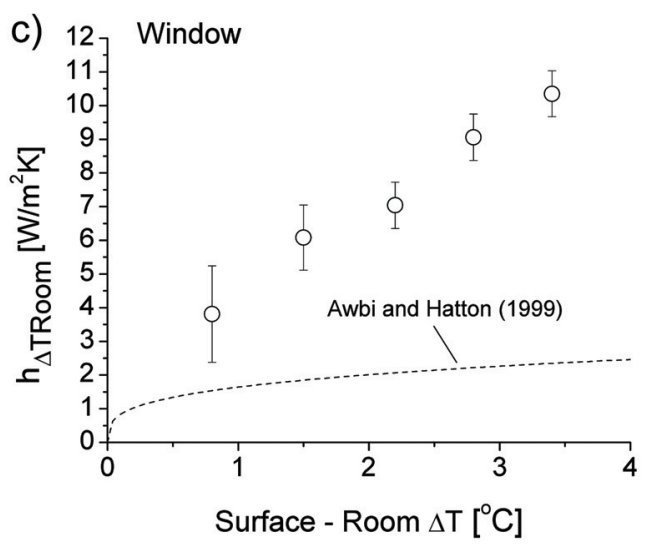

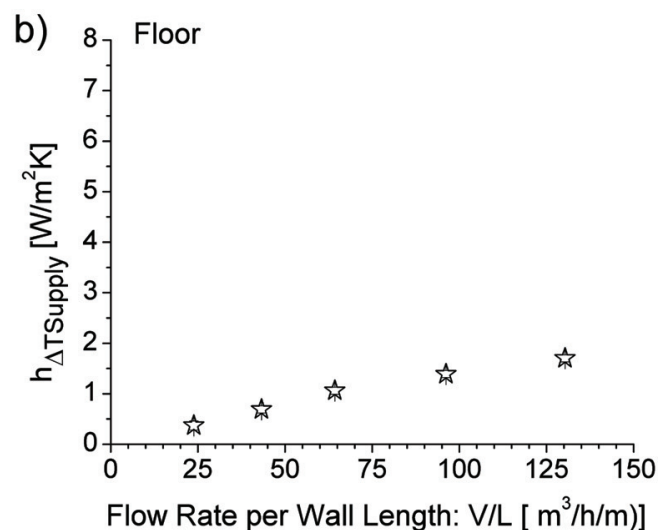

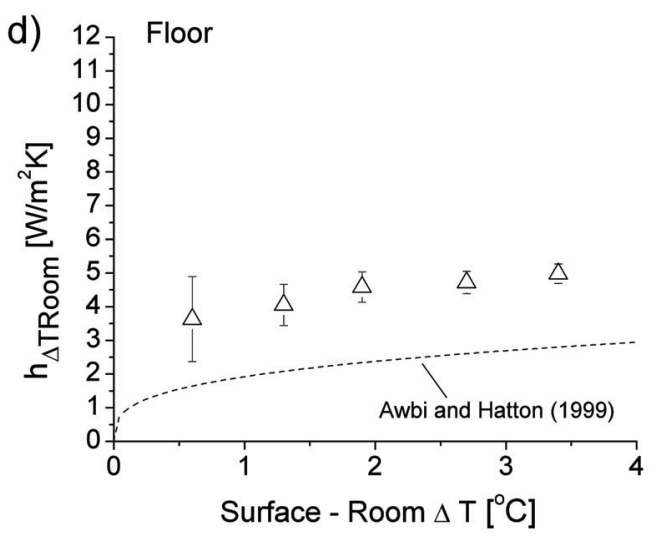

Figure 4. Forced convection at (a) the window surface and (b) the floor surface, and natural convection at (c) the window surface and (d) the floor surface. 
correlations are developed using the room temperature as a reference, there is greater variability in the convection coefficients because the temperature difference is a reflection of the degree of air mixing. In addition, the temperature difference between room and surface does not take into account the window's proximity to the jet washing the hot surface. As such, the temperature difference between window and room is quite small, and the relative uncertainty is thus much greater. Figures $4 \mathrm{c}$ and $4 \mathrm{~d}$ illustrate this showing that error bars are consistently both absolutely and relatively larger (4-34\% in the case of supply reference, and 6-68\% in the case of room temperature reference). In contrast, when the correlations are based on the constant temperature of the supply air entering the room, there is a large temperature difference from surface to supply and this provides a more accurate measurement and correlation (Figures $4 \mathrm{a}$ and $4 \mathrm{~b}$ ).

For building energy simulation programs or load calculation methods that utilize the room temperature as the reference, the correlations developed as a function of supply air temperature can easily be converted to correlations that utilize room air temperature (Equation 8). When this is used, it is assumed that the room temperature is equal to exhaust temperature in the perfect mixing condition.

The results are presented with the convective heat transfer coefficient as a function of volumetric flow because the flow rate has the strongest influence on convective heat transfer at the wall surfaces. As shown in the theoretical background section, when forced convection dominates, the convection correlation can be expressed as a function of normalized flow rate such as air change per hour ACH or simply as a function of flow rate. Figure 4 shows the difference in the presentation of results when temperature difference is based on room air and surface temperatures, with $h=f$ (Temperature Difference), versus when it is based on supply air and surface temperatures, with $h=f$ (Flow rate).

A simple way to determine the dominant convective phenomenon is to graph the results. For example, when the points are graphed based on surface-room temperature difference and follow the curve fit indicative of natural convection, the dominant phenomenon is natural convection. In order to determine the physical phenomenon associated with the graphed results, it is necessary to return to theory and utilize previous research in correlation development. Previous studies (Fisher 1995; Fisher and Pedersen 1997) show that flow on room surfaces in enclosed rooms is turbulent or transitional. For natural convection, this paper refers to the correlation developed by Awbi and Hatton (1999) based on full-scale experiments in an enclosed space. This correlation has also been experimentally validated by other researchers (Novoselac et al. 2006a).

Plots of the natural convection correlations developed by Awbi and Hatton for walls and floor $\left(h_{\text {Wall }}\right)=1.823 \cdot \Delta T^{0.293} / D h^{0.121}$ and $h_{\text {Floor }}=2.175 \cdot \Delta T^{0.308} / D h^{0.076}$, where $D h$ is height of the wall/window or hydraulic diameter of the floor) in Figures $4 \mathrm{c}$ and $4 \mathrm{~d}$ show that the convection coefficients measured at these surfaces are much higher than those corresponding to natural convection. Neither the shape nor the values of the natural convection curve for vertical surfaces correspond to those developed in this study for ceiling slot diffusers. In addition, the measured values of convection at the floor are too large to match the natural convection correlation developed by Awbi and Hatton. This indicates that forced convection has a significant role in convective heat transfer at the window and floor surfaces. When the convection coefficients are calculated based on a surface-supply temperature difference and graphed as a function of volumetric flow rate (diagrams $\mathrm{a}$ and $\mathrm{b}$ in Figure 4), and forced convection is used as the model (Equation 17), it is seen that the curves match forced convection theory very consistently.

As per the discussion above, the results of analysis for each of the studied phenomena are graphed with supply temperature as the reference and presented with the convective heat transfer coefficient as a function of volumetric flow rate. An extended discussion of the choice of volumetric flow rate will follow and will be validated in further graphs. In addition, the following 

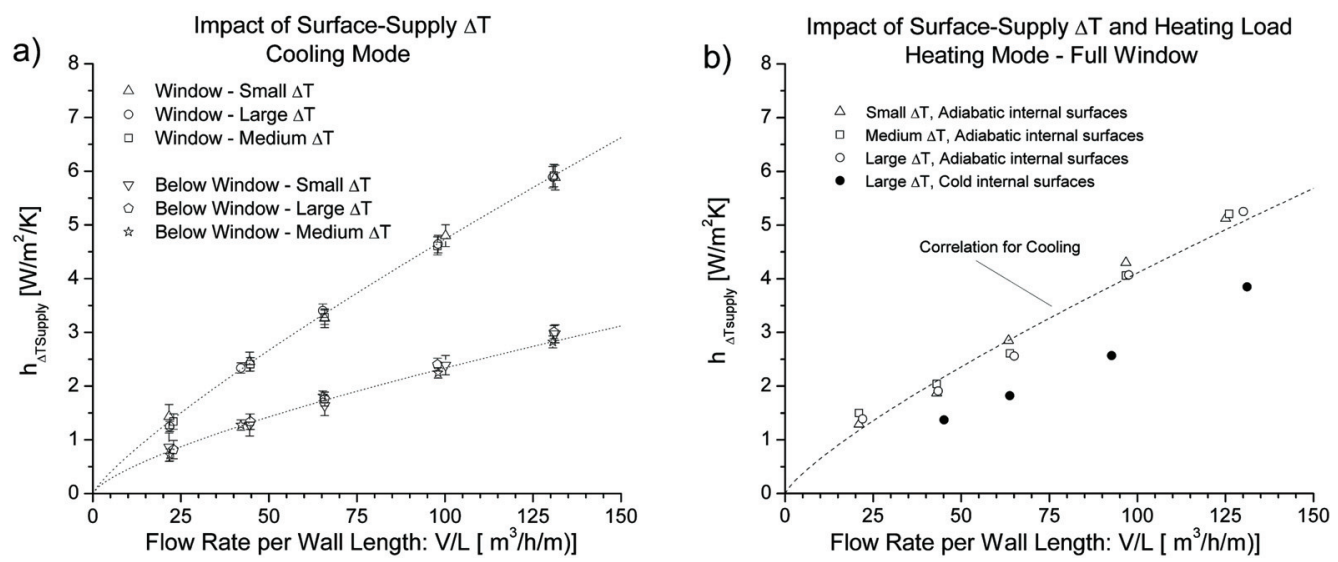

Figure 5. Impact of the temperature difference between surface and supply for (a) cooling condition and (b) heating condition.

analysis of the impact of temperature differences between surface and supply air reaffirm the lack of dependence of the correlations on temperature.

\section{Impact of Temperature Difference}

The first phenomenon studied examined the effect of temperature difference on the correlations using three different temperature differences between supply and surface temperatures. In the results shown in Figure 5a, the temperature differences between room supply and window surface correspond to small, $6.7^{\circ} \mathrm{C}$, medium, $9.8^{\circ} \mathrm{C}$, and large, $14^{\circ} \mathrm{C}$ (small, $12.1^{\circ} \mathrm{F}$, medium, $17.6^{\circ} \mathrm{F}$, and large, $\left.25.2^{\circ} \mathrm{F}\right), \Delta T \mathrm{~s}$. These values are the values measured at a specific flow rate of $\dot{V} / L=98 \mathrm{~m} / \mathrm{h} \cdot \mathrm{m}$ $(\dot{V} / L 17.6 \mathrm{cfm} / \mathrm{ft})$. For specific flow rates greater or less than $98 \mathrm{~m}^{3} / \mathrm{h} \cdot \mathrm{m}(17.6 \mathrm{cfm} / \mathrm{ft})$ the variation of these $\Delta T \mathrm{~s}$ was a maximum of $30 \%$. The tight clustering of points for different $\Delta T \mathrm{~s}$ in Figure $5 \mathrm{a}$ for all analyzed flow rates indicates that temperature difference does not affect the correlation for the window or the wall below the window.

Figure $5 \mathrm{~b}$ presents the results for the heating mode (with cool surface and hot air supply) when the entire wall was used as a window (full window) with no wall section below the window. It shows the results for the experimental case when the internal surfaces were maintained at the room temperature (adiabatic internal surfaces) and the only heating load in the room was due to the cooled window surface. Similar to the effect of temperature difference in the cooling condition, results for the case when internal surfaces are maintained at room temperature in Figure $5 \mathrm{~b}$ show that supply air-surface temperature difference has no effect on the heat transfer coefficient in the heating condition (cooled wall). Considering the fact that temperature difference between supply air and surface (DT in Figure 5) does not affect the convection at the window and wall below the window, each case for the studied phenomena to follow uses the large temperature difference condition between surface and supply with the knowledge that the correlations would be similar if the small or medium temperature difference were used.

\section{Heating vs. Cooling Mode}

Figure $5 \mathrm{~b}$ also shows the results when the internal room surfaces are cooled to mimic a window surface in the wintertime. In this case, heating load (negative heat flux) was generated from window surfaces but also from internal surfaces that were at a lower temperature than the average 
room air temperature. This generated temperature stratification in the room, which further affected the behavior of the hot supply jet and convection at the window surface. Comparison of the correlations for experiments that maintained an equal internal surface and room temperature with those that maintain cold internal surfaces (Figure 5b) shows that convection is significantly lower when the internal surfaces are cold. This could be due to the impact of cool air (due to cold internal surfaces) that approaches the jet from the room side and, in conjunction with the cool window surface affects the buoyancy forces and the direction of the hot jet. It seems that these buoyancy forces weaken the downward hot air jet and divert it towards the ceiling generating temperature stratification. The measurement of lower velocities near the window for the cases with cold internal surfaces and temperature stratification in the central space confirms this hypothesis.

Overall, the results in Figure $5 \mathrm{~b}$ indicate that correlations for the cases when ceiling slot diffusers provide space heating can be slightly or significantly different from when these diffusers are used for space cooling. This depends primarily on what is going on in the central part of the perimeter zone, or more precisely, what the temperature difference is between supply jet and room air and how much this affects the stratification in the space. The general trend detected by flow visualization is that for low flow rates such as $\dot{V} / L=45 \mathrm{~m} / \mathrm{h} \cdot \mathrm{m}(8.1 \mathrm{cfm} / \mathrm{ft})$ or lower and cold indoor surfaces, the hot supply jet is diverted toward the ceiling, and negative buoyancy in the lower part of the window appears, causing the flow to be dominated by natural convection. With low flow rates, two distinct regions of circulation currents develop. The first is upward on the upper half of the window in response to the warm air from the jet that diverted towards the ceiling. The second is downward on the lower half of the window, caused by natural convection and negative buoyancy on the cool window surface. With larger flow rates, providing $\dot{V} / L$ from 90 to $130 \mathrm{~m}^{3} / \mathrm{h} \cdot \mathrm{m}$ (from 16.2 to $23.3 \mathrm{cfm} / \mathrm{ft}$ ), the jet attaches itself to the window surface and forced convection dominates. The mix of dominant natural and forced convection at different flow rates could be a reason why the heating correlation developed as function of flow rate does not follow the shape of the correlation for forced convection as it does in the cooling regime presented in Figure 5a.

\section{Impact of Geometry}

In Figure 6, four conditions related to geometrical phenomena are examined: the position of the diffuser (6a), the size and position of the window ( $6 \mathrm{~b}$ and $6 \mathrm{c}$ ), and the effect of the addition of two types of windowsills (6d).

The experiments related to studied Phenomenon 2 examined the effect of diffuser distance from the external wall on the surface correlations; overall results are presented in Figure 6a. The experiments were performed with the diffuser at $10 \mathrm{~cm}(4 \mathrm{in}$.) and $23 \mathrm{~cm}(9 \mathrm{in}$.) from the window surface. This range is selected as a common position in commercial buildings. What may be garnered from the graph is that the convection correlations for the $10 \mathrm{~cm}$ and $23 \mathrm{~cm}(4 \mathrm{in}$. and 9 in.) diffuser positions are close enough to one another to conclude that the jet attaches to the window surface due to the Coanda effect in both cases. Therefore, the convection is independent of diffuser distance if that distance is not large (larger than $23 \mathrm{~cm}, 9$ in.). Since the distance of 23 $\mathrm{cm}$ (9 in.) leaves enough space for positioning the window blinds this distance is used for all experiments that follow.

Moving from diffuser position to window characteristics, Phenomena 4, 5 and 6 focused on geometrical modifications to the window and wall below the window (Figures 6b, 6c and 6d). In cases where the size of the window was examined (Phenomenon 4) the experimental setups either had the window correspond to the full wall or to only half of it. Figure $6 \mathrm{~b}$ shows that the convection correlations are relatively similar for the window that covers the top half of the external wall (half window) and the complete external wall (full window). The convection coefficients defined for the full window are slightly smaller than for the half window because the 

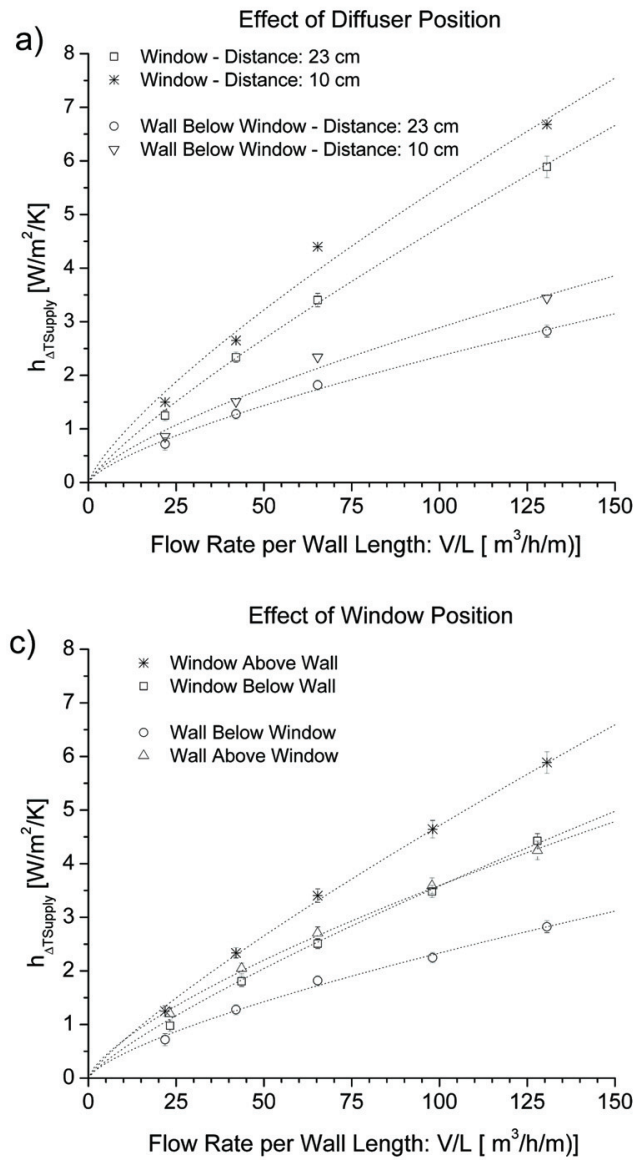

Figure 6. Impact of geometry with varying (a) diffuser positions, (b) window sizes, (c) window positions, and (d) window sills.
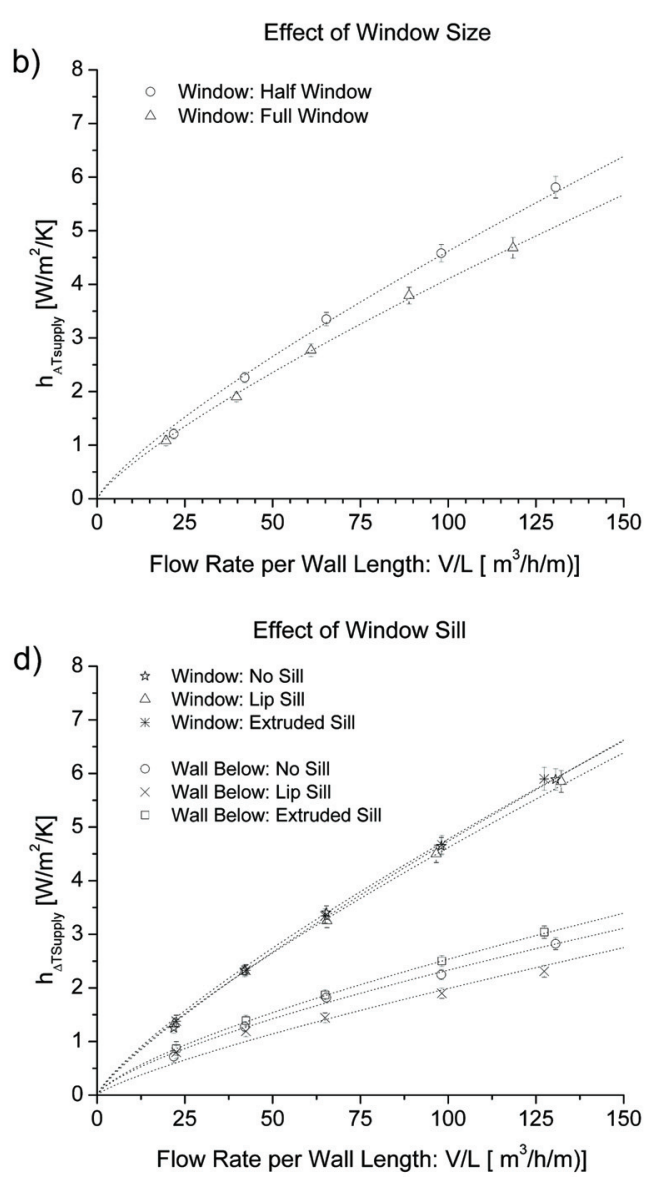

cool jet from the diffuser spreads over the larger area and the average air velocity near the full window is smaller than for the half window.

The next window characteristic studied was the placement of the window (Phenomenon 5). In these experiments, the effect of window position on the external wall was investigated. By placing a window in the lower part of the external wall, and comparing the results with the case when the window was adjacent to the ceiling, the effect of vertical distance of diffuser from the window on convective heat transfer at the window and wall was investigated. The results in Figure $6 \mathrm{c}$ show that when the window is positioned down toward the floor, there is a significant change in the heat transfer when compared to the case when the window is adjacent to the ceiling. The larger convective heat flux is for the case when the hot window is at the ceiling level, and this can be explained by the change of temperature and velocity along the supply jet. The jet is the coolest as it leaves the diffuser, and it warms and slows down as it moves down the wall, heated both by the warm surface and by entrainment of air from the room side. Therefore, the most intensive heat transfer is for the case when the hot window is adjacent to the ceiling where the cool air leaves the diffuser with high speed (window close to the ceiling). The less intense 

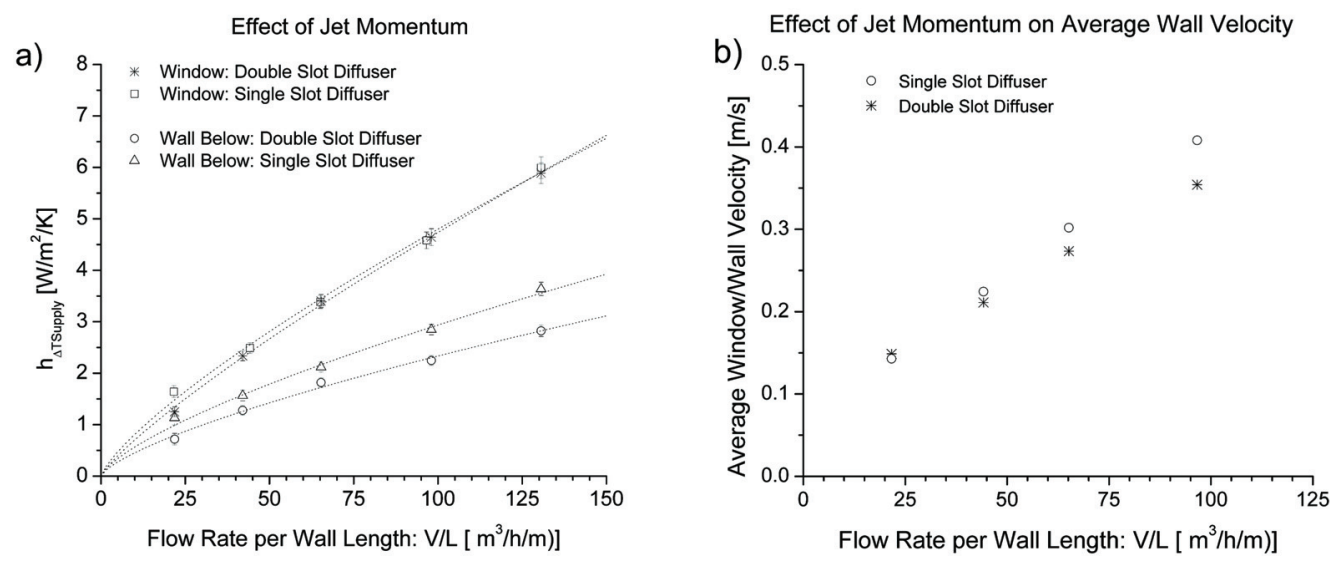

Figure 7. Impact of jet momentum on (a) convection correlation and (b) average diffuser jet velocity at window/wall.

heat transfer occurs when the hot window surface is in the lower section of the external wall as the jet air has already heated up and reduced the speed (window close to the floor). In addition, Figure $6 \mathrm{c}$ shows that in the case where the window is placed close to the floor and the wall section is above, the convection correlations for the upper wall and the window below are almost identical. The two curves are close because in the upper section (close to the wall) the jet is cold but the wall temperature is low (due to the small wall heat flux), and this enables that jet penetrates in the lower section (close to the window below the wall) without significant loss of speed. This way the two convection curves merge.

The next studied phenomenon, Phenomenon 6 with results presented in Figure 6d, looked at the effect of two types of windowsills on the correlations. The three studied cases analyzed three different experimental configurations. The first had no window sill, the second had a "lip sill" (an extrusion that was limited to only the base of the window $10 \mathrm{~cm}$ from the wall), and the third had an extruded sill (an extrusion that went all the way to the foot of the wall and extended 10 $\mathrm{cm}$ from the wall). Figure $6 \mathrm{~d}$, shows that the convection correlation at the window was not changed in the presence of the lip sill or the extruded sill, while the lip sill obstructed the downward flow along the bottom wall section, decreasing the convective heat transfer. For the extruded sill, the heat transfer was very similar to that without the sill, indicating that the flow was uninterrupted by the presence of the sill that filled the full bottom wall. The overall effects of the sills are relatively small, and do not warrant the introduction of separate convection correlations.

With respect to varying geometries, Figure 6 shows that the only geometric change that significantly influences the overall convection is the placement of the window.

\section{Impact of Jet Momentum}

Figure 7 shows the results of the investigation related to the diffuser characteristics (studied Phenomenon 3). Figure 7a presents the results from two different diffuser flow areas, a double slot and single slot diffuser. The decrease of the effective area of the diffuser to half of the initial was obtained by converting a double slot diffuser into a single slot diffuser. Since the flow rate was kept constant, the effective momentum doubled. The results of this phenomenon lead to a 
similar conclusion as those of Phenomenon 2 where the sensitivity of convection to diffuser distance from the wall was tested. The results in Figure 7a show that for the two significantly different jet momentums the convection correlation curves are almost identical for the window surface and very close for the wall below the window. As the window is generally the area of concern with respect to heat gains/losses by convection, the results show that an increase of jet momentum does not increase the convective heat transfer. For the analyzed ceiling slot diffusers convective heat transfer is much more sensitive to the flow rate than to the supply jet momentum.

The low impact of jet momentum on forced convection at window and wall surfaces can be explained by the Coanda effect and entrainment of room air near the diffuser. Due to Coanda effect, the jet attaches itself to the window and the wall, but as the jet loses velocity due to the entrainment from the room side, it is less efficient at removing heat at lower wall surfaces. This entrainment is larger for diffusers with higher momentum especially in the area close to the diffuser. This hypothesis is confirmed by the velocity measurements along the jet.

Figure $7 \mathrm{~b}$ shows the results from velocity measurement with varying jet momenta. In order to investigate whether the velocity field along the windows and wall changes with the change of supply momentum, a jet velocity distribution reading was taken at each air flow rate for the momentum produced by both single and double slot diffusers. Velocity was measured at 16 locations, four different locations along the external wall and window at four characteristic heights (Figure $2 \mathrm{a}$ ). Individual readings of velocity sensors positioned along the jet show that at a certain distance from the diffuser along the window surface, the velocities of the jet for single slot and double slot diffuser are almost the same. Figure $7 \mathrm{~b}$ shows that the change in average velocity is very small. This explains the results presented in Figure 7a, and confirms the hypothesis that for the studied geometry doubling the momentum affects only the velocity near the diffusers. The velocity in the bulk flow with the single and double slot diffusers quickly equalize.

Figure 8 shows the correlation results for the full wall window with the ceiling slot diffuser placed at the central part of the room, $1.5 \mathrm{~m}$ from the window (studied Phenomenon 10 in Table 1). This experimental setup is similar to geometry occasionally found in airports where

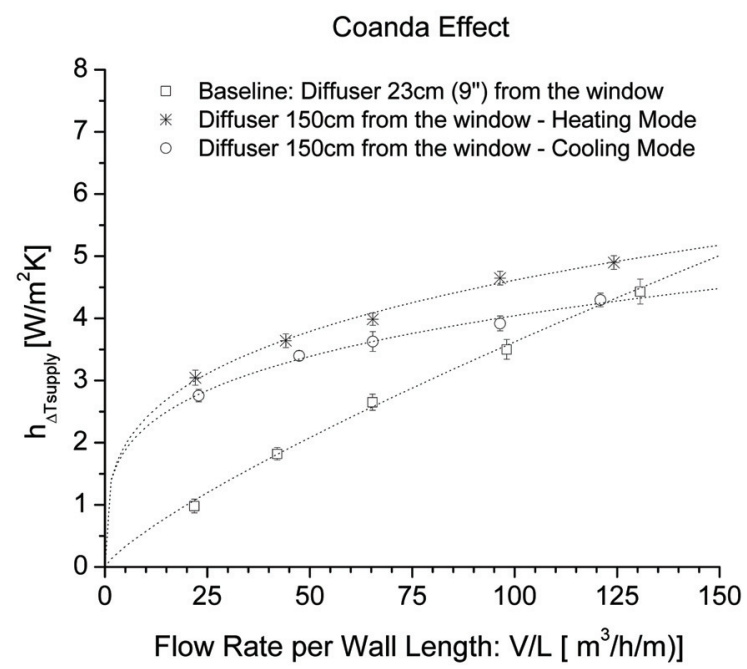

Figure 8. Effect of diffuser position and jet attachment. 
the diffuser is located along the central walkway of the terminal. This case was investigated to look at the applicability of the correlations developed for the ceiling slot diffuser placed at 23 $\mathrm{cm}(9$ in.) when the diffuser is moved to a more central location. As shown before, the $23 \mathrm{~cm}(9$ in.) condition is highly influenced by the Coanda effect. On the other hand, the results for the heating and cooling conditions with the diffuser positioned further from the window show a strong influence from natural convection, especially at low flow rates. This conclusion is based on the comparison of the curve fit in Figure 8 with natural convection theory (Equations 9 and 10). The curve fits for the central diffuser in Figure 8 have exponents of 0.25 and 0.28 , which is between the predicted values from Equations 9 and 10. As such, it is inappropriate to utilize the results of this paper and generalize the correlations when the ceiling slot diffuser is positioned further away from the window and wall surface.

\section{Convection Correlations for Floor Surfaces}

While all of the previous graphs refer to correlations developed for the window and wall below the window, correlations were also developed for the floor surface. This was done as the characteristic flow from the ceiling slot diffuser also influences the flow at the floor surface. Figure 9 shows the results associated with the floors. Figure 9 shows a tight clustering of the convection correlations for the floor area for several characteristic phenomena. This indicates that convection at the level of the floor is unaffected by changes to the diffuser, diffuser jet or window. Essentially, any change in the flow field identified at the window and the wall below the window has leveled itself out by the time it reaches the floor. The impact of natural convection on $h$ at the floor surfaces is detectable in Figure 9 through the high $h$ values for the case with large $\Delta T$ (small $\Delta T$ vs. medium $\Delta T$ vs. large $\Delta T)$. However, the stronger dependency of $h$ on the specific flow rate $\dot{V} / L$ rather than on $\Delta T$ still indicates the dominance of forced convection at the floor surfaces.

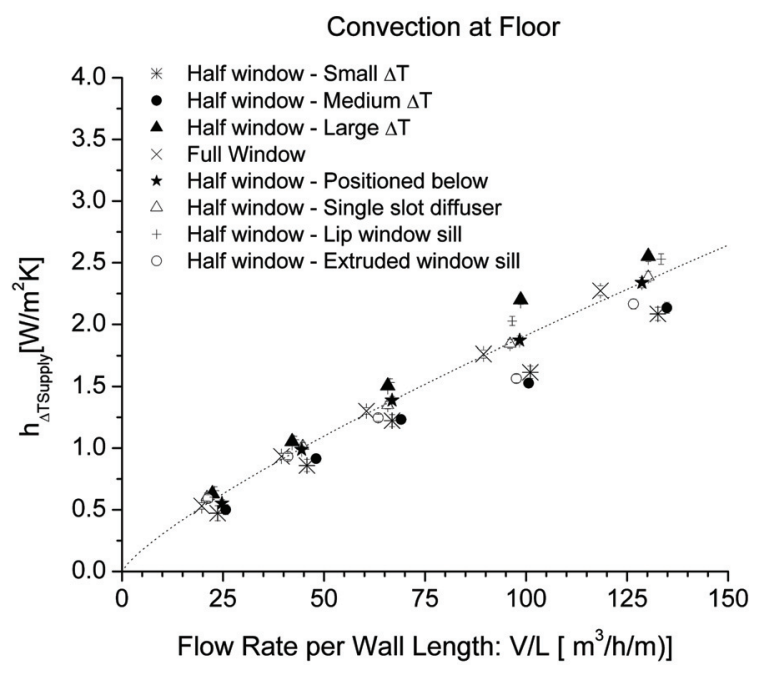

Figure 9. Convection at floor surfaces. (Note: Flow rates slightly offset for clarity.) 

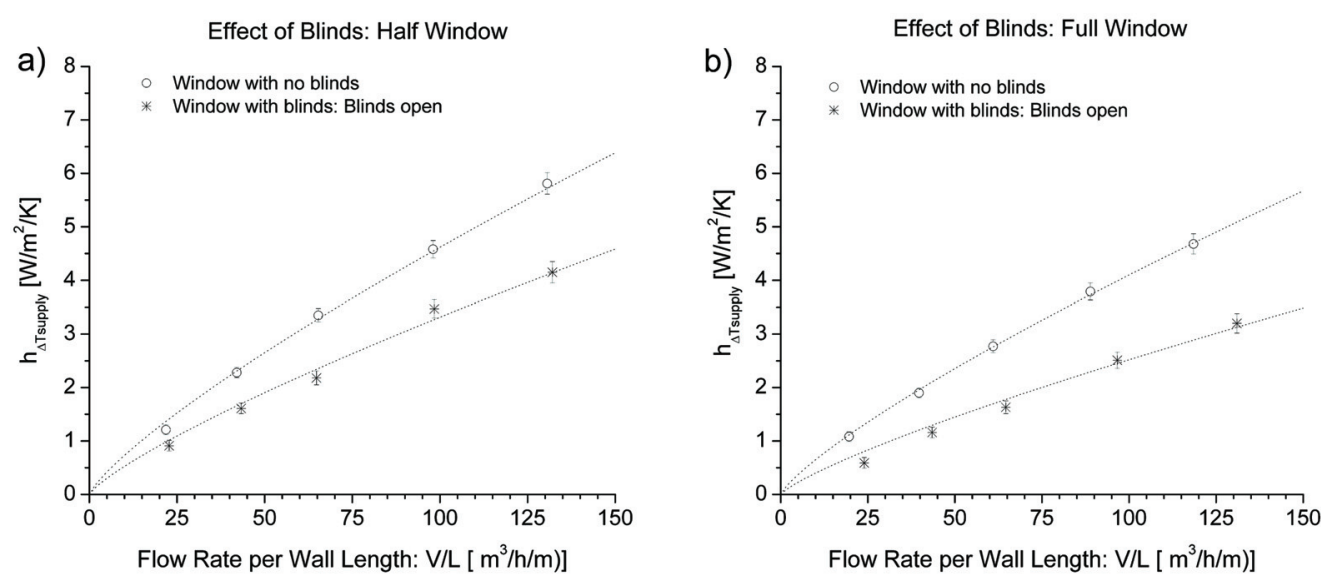

Figure 10. Convection correlations with and without venetian blinds examining the effect of blinds on (a) half windows and (b) full windows.

\section{Convection Correlations for Window with Blinds}

Examined phenomenon 7 looked at the characteristics of venetian blinds and their effect on the window correlations. Figure 10 shows the effect that the blinds have on the magnitude of convection with both a full and half window. The graph in Figure 10a, shows the effect of the blinds added to the half window while Figure 10b shows the effect of the blinds on the full window.

From Figure 10, it is evident that the presence of blinds significantly decreases the magnitude of convection. The hypothesis for this is that the fully open blinds act as a barrier between the diffuser flow and the window, hindering the contact between the two media. The convection at the full window is lower than that of the half window both with and without blinds. This is expected, as the most significant convection occurs with the largest temperature differences. This large temperature difference occurs at the top half of the window and decreases as the jet warms and moves toward the bottom. Even if this surface is hot, as in the case of the full window, the temperature difference is smaller. As such, when averaged over the whole surface, the convection is greater with the half window, both with and without blinds. In addition, blinds decrease the convective coefficient at floor surfaces. However, this decrease is relatively small $(\sim 15 \%)$ and it is in the scattering range of experimental results presented in Figure 9.

\section{IMPLICATIONS}

In the following sections, the newly developed convection correlations are summarized along with their applicability to various surfaces for each investigated phenomena. The next section discusses the implications of each correlation, and their impact on the overall cooling load and heat transfer through the building envelope.

\section{New Convection Correlations}

All the correlations associated with the graphs in the text are summarized in Table 2. There are eight new correlations developed for: (a) windows where approximately half of the external wall is window and window surface is in the upper (above) or lower (below) part of the external 
Table 2. New Indoor Convection Correlations Based on $\Delta T$ Supply

\begin{tabular}{ccccc}
\hline Description Index & $\begin{array}{c}\text { SI Correlation } \\
{\left[\mathrm{W} / \mathrm{m}^{2} \cdot \mathrm{K}\right]}\end{array}$ & $\begin{array}{c}\text { IP Correlation } \\
{\left[\mathrm{Btu} / \mathrm{h} \cdot \mathrm{ft}^{2} \cdot{ }^{\circ} \mathrm{F}\right]}\end{array}$ & $\begin{array}{c}\text { Experiment } \\
\text { Description }\end{array}$ & Implications \\
\hline \hline
\end{tabular}

a) Half Window-No Blinds

\begin{tabular}{c|c|c|c|c|c}
\hline $\begin{array}{c}\text { Window } \\
\text { Above }\end{array}$ & I & $h=0.117(\dot{V} / L)^{0.8}$ & $h=0.079(\dot{V} / L)^{0.8}$ & $\begin{array}{c}\text { Single/double slot dif- } \\
\text { fusers, } 10 \mathrm{~cm} \text { and } 23 \mathrm{~cm} \\
(4 \text { in. and } 9 \text { in. }) \text { from } \\
\text { window, lip, and } \\
\text { extruded sills }\end{array}$ & $\begin{array}{c}\text { Correlation insen- } \\
\text { sitive to diffuser } \\
\text { position, momen- } \\
\text { tum, and sill }\end{array}$ \\
\hline $\begin{array}{c}\text { Window } \\
\text { Below }\end{array}$ & II & $h=0.093(\dot{V} / L)^{0.8}$ & $h=0.063(\dot{V} / L)^{0.8}$ & $\begin{array}{c}\text { Window below, no sill, } \\
\text { double slot diffuser 23 } \\
\mathrm{cm}(9 \text { in.) from wall }\end{array}$ & $\begin{array}{c}\text { Correlation } \\
\text { sensitive to win- } \\
\text { dow position }\end{array}$ \\
\hline
\end{tabular}

b) Full Window-No Blinds

\begin{tabular}{c|c|c|c|c|c}
\hline $\begin{array}{c}\text { Full } \\
\text { Window }\end{array}$ & III & $h=0.103(\dot{V} / L)^{0.8}$ & $h=0.70(\dot{V} / L)^{0.8}$ & $\begin{array}{c}\text { Whole external wall is } \\
\text { window, no sill, double } \\
\text { slot diffuser } 23 \mathrm{~cm}(9 \\
\text { in.) from wall }\end{array}$ & $\begin{array}{c}\text { Correlation } \\
\text { sensitive to size of } \\
\text { window }\end{array}$ \\
\hline
\end{tabular}

c) Half Window-With Blinds

\begin{tabular}{c|c|c|c|c|c}
\hline $\begin{array}{c}\text { Window } \\
\text { Above }\end{array}$ & IV & $h=0.083(\dot{V} / L)^{0.8}$ & $h=0.056(\dot{V} / L)^{0.8}$ & $\begin{array}{c}\text { Blinds open, no sill, } \\
\text { double slot diffuser 23 } \\
\mathrm{cm}(9 \text { in.) from wall }\end{array}$ & $\begin{array}{c}\text { Correlation } \\
\text { sensitive to pres- } \\
\text { ence of blinds }\end{array}$ \\
\hline
\end{tabular}

d) Full Window-With Blinds

\begin{tabular}{c|c|c|c|c|c}
\hline $\begin{array}{c}\text { Full } \\
\text { Window }\end{array}$ & $\mathrm{V}$ & $h=0.063(\dot{V} / L)^{0.8}$ & $h=0.043(\dot{V} / L)^{0.8}$ & $\begin{array}{c}\text { Blinds open, whole } \\
\text { external wall is window, } \\
\text { double slot diffuser 23 } \\
\text { cm (9 in.) from wall }\end{array}$ & $\begin{array}{c}\text { Correlation } \\
\text { sensitive to pres- } \\
\text { ence of blinds }\end{array}$ \\
\hline
\end{tabular}

e) External Wall

\begin{tabular}{|c|c|c|c|c|c|}
\hline $\begin{array}{c}\text { Below } \\
\text { Window }\end{array}$ & VI & $h=0.063(\dot{V} / L)^{0.8}$ & $h=0.043(\dot{V} / L)^{0.8}$ & $\begin{array}{l}\text { Single/double slot, } 10 \\
\mathrm{~cm} \text { and } 23 \mathrm{~cm} \text { ( } 4 \mathrm{in} . \text { and } \\
9 \text { in.) from window, lip } \\
\text { and extruded sills, } \\
\text { with/without blinds }\end{array}$ & $\begin{array}{l}\text { Correlation insen- } \\
\text { sitive to diffuser } \\
\text { position, momen- } \\
\text { tum, sill, and } \\
\text { blinds }\end{array}$ \\
\hline $\begin{array}{l}\text { Above } \\
\text { Window }\end{array}$ & VII & $h=0.093(\dot{V} / L)^{0.8}$ & $h=0.063(\dot{V} / L)^{0.8}$ & $\begin{array}{c}\text { Double slot diffusers } 23 \\
\mathrm{~cm} \text { (9 in.) from wall, no } \\
\text { blinds, no sill }\end{array}$ & $\begin{array}{l}\text { Correlation } \\
\text { sensitive to win- } \\
\text { dow position }\end{array}$ \\
\hline \multicolumn{6}{|l|}{ f) Floor } \\
\hline $\begin{array}{l}\text { All } \\
\text { Window } \\
\text { Positions }\end{array}$ & VIII & $h=0.048(\dot{V} / L)^{0.8}$ & $h=0.033(\dot{V} / L)^{0.8}$ & $\begin{array}{l}\text { Single/double slot, } 10 \\
\mathrm{~cm} \text { and } 23 \mathrm{~cm} \text { ( } 4 \text { in. and } \\
9 \text { in.) from window, lip } \\
\text { and extruded sills, } \\
\text { with/without blinds }\end{array}$ & $\begin{array}{c}\text { Correlation } \\
\text { insensitive to win- } \\
\text { dow and diffuser } \\
\text { geometry }\end{array}$ \\
\hline
\end{tabular}

Note: $\dot{V} / L$ equals volumetric flow rate per unit of length of an external wall with ceiling slot diffusers, where SI units is given in $\mathrm{m}^{3} / \mathrm{h} \cdot \mathrm{m}$ and I-P units are given in $\mathrm{cfm} / \mathrm{ft}$. 
wall (Correlations I and II), (b) windows that occupy the whole external wall (Correlation III), (c) half windows in the upper part of the external wall with blinds (Correlation IV), (d) full windows with blinds (Correlation V), (e) walls with and without blinds positioned below (correlation VI) and above the window (Correlation VII) and (f) floors (Correlation VIII). The "Correlation" column in Table 2 summarizes all of the constant coefficients associated with the correlation expressed by Equation 17 when the correlation exponent is associated with forced convection $(n=0.8)$. The Implications column expresses what each of the correlations imparts in greater detail.

The new correlations in Table 2 may be explained in the following manner. The lettered rows list what is being studied, a half window, full window, or wall, with blinds present or absent. The roman numerals then represent the surface in question to which the correlation corresponds. For example, if the lettered row states "Half Window-No Blinds" and the roman numeral, "Window Below", the correlation is for a half window, placed on the lower half of the wall section without blinds. Table 2 also shows that the primary distinctions can be made between: 1) window and wall, 2) window in the upper or lower part of the external wall, 3) half and full window, and 4) window with and without blinds.

The difference in the correlations for the window and wall positioned at the same place (both on the lower or upper half of the external wall section, Correlation I and VII and Correlation II and VI) can be explained by the difference in the heat flux distribution. The window has approximately two to three times larger convective heat flux than the wall below the window. In the case when the window is placed below, (Correlation II and VII), the buoyancy from the window below affects the airflow at the wall above due to the fact that buoyancy acts in the opposite direction from the supply jet momentum force. When the window is above the wall (Correlation I and VI) the effect of buoyancy from the lower part of the external wall section on the upper part is significantly smaller. This could be the root of the difference between Correlations I and VII and Correlations II and VI.

Changes in the jet velocity as it moves downward along the window surface could be the explanation for the difference between the correlations for window above and window below (Correlation I and II). This is because there is a large entrainment of room air into the jet that attaches itself to the external wall/window. This causes the jet velocity to decrease as the jet flows towards the floor. As such, the convective heat transfer is reduced at the surfaces further away from the diffuser. For the cases with a half-window, the placement of the window in the external wall significantly affects the convection correlations for both window and wall.

The difference in correlations for full and half-window imparts the fact that window size plays a role in the cases with and without blinds (Correlation I and III). The full window's lower convective heat transfer coefficient may be explained by the difference in average velocity in the cases with full and half-windows. When the air speed is averaged over the entire window surface, it is smaller than the average for the upper half of the window, and the convection is lessened in relation to that with only the half-window.

The presence of blinds influences the heat transfer at window surfaces. The difference in the correlations for windows with and without blinds (Correlation I and VI and Correlations III and $\mathrm{V}$ ) is caused by the specific airflow around the blinds. When the blinds are present, they act as a barrier between the jet flow and the window and decrease the overall convective heat transfer. In the case of the half-window with blinds, and wall below the blinds the impact of blinds on the wall below is negligible. Once the flow reaches the wall below the window and the blinds are no longer present, the heat transfer properties are the same such as in the case without the blinds (Correlation VI does not depend on blinds).

All correlations in Table 2 are developed for cooling with slot diffusers. As the results presented in Figure $5 \mathrm{~b}$ indicate, they can be sensitive to operation regime (heating vs. cooling). 
Before the correlations from Table 2 are to be applied in the heating condition, more experimentation with a larger range of temperature differences, coupled with flow visualization along the window surface is needed.

\section{New vs. Old Convection Correlations and Impact on Overall Heat Transfer Calculation}

The change in overall heat transfer through windows or external walls due to differences in convection correlations is not limited solely to convective heat transfer. For example, at the window/wall surface, when convection is increased or decreased, the temperature of the surface will change. This in turn changes the magnitude of conduction through the window/wall surface, as well as the radiative heat transfer between the window/wall surface and the rest of the interior surfaces of the room (Muneer et al. 1997). As such, the only way to accurately quantify the impact and significance of the new correlations on the overall heat transfer is to: 1) create a whole room model that includes all aspects of heat transfer (conduction, convection, and radiation), 2) implement the new and old convection correlations in this model, and 3) compare the results considering including both load and energy consumption. To quantify the significance of the new convection correlations on the overall heat transfer, the equations were implemented into an energy modeling software program, "BEAF" (Novoselac 2005) previously developed for coupling energy and airflow modeling and tested by Building Energy Simulation TEST (BESTES; Judkoff and Neymark 1995).

The energy analysis simulated the room of a building with the same dimensions as the test chamber described in the methodology section. However, the room was positioned in an office building where five sides of the room shared walls with other internal rooms, and the external wall containing a double-glazed window was oriented towards the south. The interior sidewalls were modeled as $0.01 \mathrm{~m}$ ( $0.4 \mathrm{in}$.) thick drywall, and the floor/ceiling construction included $0.02 \mathrm{~m}$ ceiling tiles, $0.1 \mathrm{~m}$ of concrete structure, and $0.01 \mathrm{~m}(0.4 \mathrm{in}$.) carpet. The exterior wall below the window consisted of $0.1 \mathrm{~m}$ of exterior brick, $0.03 \mathrm{~m}$ of insulation, and dry wall $0.01 \mathrm{~m}$ (0.4 in.) thick. The internal loads included three occupants $(80 \mathrm{~W}, 273 \mathrm{Btu} / \mathrm{h}$ each) within the building from 9 a.m. to 5 p.m., computers $(300 \mathrm{~W}, 1023 \mathrm{Btu} / \mathrm{h})$ that were left on 24 hours a day, and, internal lighting $(150 \mathrm{~W}, 512 \mathrm{Btu} / \mathrm{h}$ ), on from 6 p.m. to 12 a.m. and from 6 a.m. to 9 a.m. in the morning. An infiltration rate of 0.25 ach was also included.

The comparison of the correlations implemented in energy modeling software is provided in Table 3. The cooling load and energy analysis was conducted for the climate of Chicago, in the cooling season considered to be April 1-September 30. Three sets of correlations were analyzed. The first set assumes constant convection at all surfaces, (for example $3.2 \mathrm{~W} / \mathrm{m}^{2}\left(1.03 \mathrm{Btu} / \mathrm{hr} \cdot \mathrm{ft}^{2}\right.$ ) for vertical surfaces). These constant convection coefficients were chosen because these coefficients are often used in early energy modeling software programs. The second set uses correlations developed by Fisher and Pedersen (1997) which correlates $h$ to the ACH in the room. This was chosen due to the current prevalence of these correlations in the more detailed building energy simulation software products (Clarke 2001). The third set of correlations is representative of the current work (Table 2, Window Above, Window, and Wall Below Window). As a note, Fisher and Pedersen developed their correlations for use with radial ceiling diffusers placed at central locations within the room while the correlations developed in this paper are for ceiling slot diffusers $23 \mathrm{~cm}$ or less from the window surface where the Coanda effect dominates.

It is important to note that natural convection needs to be considered in the energy modeling which is based on $\Delta T$ between surface and room air. The outside temperature can be below the indoor design temperature, but due to internal loads, there is significant heat generation and thus a need for cooling. If $h$ is based solely on forced convection, $h$ will go to zero when the outdoor temperature is less than the design temperature. The energy model used for this study chose 
(C) 2010 American Society of Heating, Refrigerating and Air-Conditioning Engineers, Inc. (www.ashrae.org).

Published in HVAC\&R Research (Vol. 16, Issue 5, September 2010). For personal use only. Additional reproduction, distribution, or transmission in either print or digital form is not permitted without ASHRAE's prior written permission.

Table 3. Effect of Different Convection Correlations on

Temperature and Heat Flux Calculation

(Chicago: April 1 to September 30)

\begin{tabular}{|c|c|c|c|c|c|c|c|c|}
\hline Correlation & $\begin{array}{c}\text { Wall } \\
\text { U-Value }\end{array}$ & $\begin{array}{l}\text { Window } \\
\text { U-Value }\end{array}$ & $\begin{array}{l}\text { Peak } \\
\text { Load }\end{array}$ & $\begin{array}{c}\text { Seasonal } \\
\text { Energy }\end{array}$ & $\begin{array}{c}\text { Envelope } \\
\text { Energy }\end{array}$ & $\begin{array}{c}\text { Seasonal } \\
\text { MRT }\end{array}$ & $\begin{array}{c}\text { Seasonal } \\
\text { Window } \\
\mathbf{T}\end{array}$ & $\begin{array}{c}\text { Seasonal } \\
\text { Max } \\
\text { Wind. T }\end{array}$ \\
\hline SI & $\mathbf{W} / \mathbf{m}^{2} \cdot \mathbf{K}$ & $\mathbf{W} / \mathbf{m}^{2} \cdot \mathbf{K}$ & $\mathbf{W} / \mathbf{m}^{2}$ & $\mathbf{k W h} / \mathbf{m}^{2}$ & $\mathbf{k W h} / \mathbf{m}^{2}$ & ${ }^{\circ} \mathrm{C}$ & ${ }^{\circ} \mathrm{C}$ & ${ }^{\circ} \mathbf{C}$ \\
\hline $\begin{array}{c}\text { Constant } \\
\text { Coefficient } \\
3.2 \mathrm{~W} / \mathrm{m}^{2} \cdot \mathrm{K}\end{array}$ & 0.70 & 1.75 & 67.5 & 89.7 & 22.2 & 23.1 & 21.5 & 28.5 \\
\hline $\begin{array}{l}\text { Correlation } \\
\text { for Standard } \\
\text { Ceiling Diff. }\end{array}$ & 0.71 & 1.79 & 76.6 & 91.6 & 24.2 & 22.6 & 20.8 & 28.1 \\
\hline $\begin{array}{c}\text { New } \\
\text { Correlation } \\
\text { for Ceiling } \\
\text { Slot } \\
\text { Diffuser }\end{array}$ & 0.74 & 2.08 & 83.5 & 93.2 & 25.8 & 22.7 & 20.5 & 25.4 \\
\hline I-P & Btu/h$\cdot \mathbf{f t}^{2} \cdot{ }^{\circ} F$ & Btu/h$\cdot \mathbf{f t}^{2} \cdot{ }^{\circ} \mathrm{F}$ & $\mathrm{Btu} / \mathbf{h} \cdot \mathbf{f t}^{2}$ & Btu/ft ${ }^{2}$ & Btu/ft ${ }^{2}$ & ${ }^{\circ} \mathbf{F}$ & ${ }^{\circ} \mathbf{F}$ & ${ }^{\circ} \mathbf{F}$ \\
\hline $\begin{array}{c}\text { Constant } \\
\text { Coefficient } \\
0.56 \\
\text { Btu } / \mathbf{h} \cdot \mathrm{ft}^{2}{ }^{\circ} \mathrm{F}\end{array}$ & 0.123 & 0.308 & 21.4 & 28435 & 7037 & 73.6 & 70.7 & 83.3 \\
\hline $\begin{array}{l}\text { Correlation } \\
\text { for Standard } \\
\text { Ceiling Diff. }\end{array}$ & 0.125 & 0.315 & 24.3 & 29037 & 7671 & 72.7 & 69.4 & 82.6 \\
\hline $\begin{array}{c}\text { New } \\
\text { Correlation } \\
\text { for Ceiling } \\
\text { Slot } \\
\text { Diffuser }\end{array}$ & 0.130 & 0.366 & 26.5 & 29544 & 8179 & 72.9 & 68.9 & 77.7 \\
\hline
\end{tabular}

either all natural or all forced convection, $h=\max$ (forced, natural). As the winter season depends on many factors such as which HVAC system is used (fan coil, baseboard heaters, or all air system), this example of heat transfer with different correlation will only include the analysis of cooling load and energy consumption in the cooling condition.

The U-values in Table 3 show the impact of the internal convection coefficient on total conductive heat transfer, which can be used for a steady-state load calculation in winter time. On the external and internal surfaces, both radiative and convective heat transfer coefficients are included in the U-values of both the window and the wall. Convection correlations come into play in the calculation of convective heat transfer at the internal surface; these are the only values that change the R-values in columns 1 and 2 of Table 3. The convective coefficients used in these U-values are calculated with an assumed ventilation rate of 8 ach and are converted from $h_{\text {Supply }}$ to $h_{\text {Room }}$ by Equation 8 . In this conversion, the window-supply air temperature difference 
is assumed to be $9^{\circ} \mathrm{C}\left(16.2^{\circ} \mathrm{F}\right)$, while the window-room temperature difference is assumed to be $3^{\circ} \mathrm{C}\left(5.4^{\circ} \mathrm{F}\right)$. The variation of $\mathrm{U}$-values in columns 1 and 2 shows that the more accurate convection coefficients for walls and windows with slot diffusers calculate up to $19 \%$ higher steady heat conduction through windows and up to $5 \%$ for walls.

The unsteady-state heat transfer analysis for the summer condition shows that the peak loads for all cases fall on September 27 at 3 p.m. The late nature of this peak is due to the lower and thus more direct position of the sun in the Northern latitude. The peak cooling load is highest with the new correlations and lowest with the assumption of a constant convection coefficient (column 4 in Table 3 shows the cooling load per unit of floor). In addition, the new convection correlations affect the accuracy of the calculation of the total energy used in the cooling season (columns 5 and 6 in Table 3 show the seasonal energy consumption normalized by floor area). While these values are only a few percent different from one another (up to 4\%), the differences due to the varying correlations are more evident when looking at the load through only the envelope (up to $16 \%$ ). When the loads, due to internal sources, and infiltration are removed, what is left is the energy demand, per square foot due to heat gain through the envelope. The cooler window surface due to the cool jet has a very large influence on the magnitude of this load. Since the supply jet cools the window surface, the $\Delta T$ between external and internal surface is greater, and the radiative heat transfer is increased accordingly. The cooler room surface also changes the radiative and convective interactions between the other internal surfaces and indoor air, respectively. The mean radiant temperature (MRT in Table 3 ) is included as a variable in Table 3, because it influences the thermal comfort of occupants. Results show that, while the ceiling slot diffusers can have a negative effect on the energy consumption, they can have positive effect on thermal comfort by decreasing MRT in the space.

It is important to note that the values in Table 3 simply serve to illustrate the effect that the new correlations can have on the accuracy of the load calculations and energy analyses. The numerical values in Table 3 should be used only relatively and not absolutely. To estimate the impact that the new correlations have on the accuracy of energy modeling, a more detailed analysis at different locations with various building geometries is necessary.

Comparison of heat transfer calculated by 1 ) old convection coefficients for natural convection $\left(h=3.2 \mathrm{~W} / \mathrm{m}^{2} \cdot \mathrm{K}, 0.56 \mathrm{Btu} / \mathrm{h} \cdot \mathrm{ft}^{2}\right)$ in Table 3 and 2) new convection correlations (last row in Table 3 ) show the trend of increased cooling load and energy consumption with ceiling slot diffusers when compared to natural convection with no diffusers. This trend should be further analyzed, especially at the present time when more accurate convective heat transfer models for forced convection with ceiling slot diffusers are available.

\section{CONCLUSION}

This paper examined convective correlations for the indoor environment focusing on office buildings with large glazing areas and ceiling slot diffusers. This study shows that when ceiling slot diffusers are near a window surface $(23 \mathrm{~cm}$ or less) the Coanda effect is consistently exhibited and forced convection is dominant. For the cooling regime, this phenomenon was identified even at low specific supply airflow rates such as $(\dot{V} / L)=25 \mathrm{~m}^{3} / \mathrm{h} \cdot \mathrm{m}(4.5 \mathrm{cfm} / \mathrm{ft})$. Study results also show that the appropriate reference temperature suitable for correlation development is the temperature of the room supply air. Thus, all new correlations were developed as a function of specific volumetric flow rate, with the room supply and surface temperature as the reference temperature difference.

The presence of open blinds was also examined. It was found that besides the supply air flow rate the only relevant parameter that significantly affects the convection correlations is the position of the window in the external wall and the presence of the blinds. In addition, the study examined the convective heat transfer at indoor surfaces with ceiling diffusers used for 
heating (heating mode). The results show that correlations for heating mode can be slightly or significantly different from correlations for the cooling condition, depending on the temperature field in the central part of the perimeter zone.

Overall, seven new correlations were developed for integration into building load calculations and energy simulation tools. Furthermore, to define the applicability of new correlations, the study examined the application of these correlations for slot diffusers positioned in a central area of the room. These experiments found that the new results are valid for situations wherein the diffuser is suitably close to the window surface such that the jet attaches itself to the surface due to the Coanda effect. When the diffuser is placed in a central part of a room, natural convection plays a larger role in the overall convection and the newly developed correlations are no longer applicable.

In the example study of a Chicago building, the impact of the new correlations on the calculation of overall seasonal energy demand is $4 \%$ over the constant coefficient assumption and $1.7 \%$ over the correlations previously developed for standard ceiling diffusers. More significantly, these percentages increase to $16 \%$ and $6.6 \%$, when examining energy demand due to the envelope alone. In addition, the peak of total cooling load is increased by $24 \%$ and $9 \%$ over the constant coefficient and correlation for standard ceiling diffusers, which has a significant impact on the sizing of HVAC systems for perimeter building zones.

\section{ACKNOWLEDGMENTS}

The American Society of Heating, Refrigerating and Air-Conditioning Engineers and an ASHRAE Graduate Student Grant-in-Aid award provided funding for this research. The authors thank the members of the RP-1416 Project Monitoring Subcommittee for their useful suggestions and advice. Also, the authors thank Dr. Leen Peeters from the University of Brussels for the manuscript review and constructive comments.

\section{REFERENCES}

ASHRAE. 2000. ASHRAE Guideline 2, Engineering Analysis of Experimental Data. Atlanta: American Society of Heating, Refrigerating and Air Conditioning Engineers.

ASHRAE. 2009. 2009 ASHRAE Handbook-Fundamentals. Atlanta: American Society of Heating, Refrigerating and Air Conditioning Engineers.

Alamdari, F., G.P. Hammond, and L. Melo. 1984. Appropriate calculation methods for convective heat transfer from building surfaces. Proceedings of the U.K. National Conference on Heat Transfer, Leeds, United Kingdom 2: 1201-11.

Awbi, H.B. 1998. Calculation of convective heat transfer coefficients of room surfaces for natural convection. Energy and Buildings 28(2):219-27.

Awbi, H.B. 2003. Ventilation of Buildings, 2nd Ed. London: Taylor and Francis Books, Ltd.

Awbi, H.B., and A. Hatton. 1999. Natural convection from heated room surfaces. Energy and Buildings 30(3):233-44.

Awbi, H.B., and A. Hatton. 2000. Mixed convection from heated room surfaces. Energy and Buildings 32(2):153-66.

Beausoleil-Morrison, I., and P. Strachan. 1999. On the significance of modeling internal surface convection in dynamic whole-building simulation programs. ASHRAE Transactions 105(2):929-40.

Bejan, A. 2004. Convection Heat Transfer, 3rd ed. Hoboken, NJ: John Wiley and Sons, Inc.

Chen, Q., C.A. Mayers, and J. Van der Kooi. 1989. Convective heat transfer in rooms with mixed convection. International Seminar on Indoor Air Flow Patterns, University of Liege, Belgium, 69-82.

Clarke, J.A. 1991. Internal convective heat transfer coefficients: A sensitivity study. Report to ETSU, University of Strathclyde, Glasgow U.K.

Clarke, J.A. 2001. Energy Simulation in Building Design. Boston: Buttersworth-Heinman.

Collins, M. 2005. Evaluation of an approximate method for predicting the $U$ value of a window with a between-panes blind, Numerical Heat Transfer 47: 233-50. 
Collins, M., S. Tasnim, and J. Wright. 2008. Determination of convective heat transfer for fenestration with between-the-glass louvered shades. International Journal of Heat and Mass Transfer 51(11-12):2742-51.

Fisher, D. 1995. An experimental investigation of mixed convection heat transfer in a rectangular enclosure. $\mathrm{PhD}$ thesis, Department of Mechanical Engineering, University of Illinois at Urbana-Champaign, Urbana-Champaign, IL.

Fisher, D., and C.O. Pedersen. 1997. Convective heat transfer in building energy and thermal load calculations. ASHRAE Transactions 103(2):137-48.

Judkoff, R., and J. Neymark. 1995. International Energy Agency Building Energy Simulation Test (BESTEST) and Diagnostic Method, IEA Energy Conservation in Buildings and Community Systems Programme Annex 21 Subtask C and IEA Solar Heating and Cooling Programme Task 12 Subtask B.

Khalifa, A.J.N., and R.H. Marshall. 1990. Validation of heat transfer coefficients on interior building surfaces using a real-sized indoor test cell. Int. J. Heat Mass Transfer 33(10):2219-36.

Lomas, K. 1996. The UK applicability study: An evaluation of thermal simulation programs for passive solar house design. Building and Environment 31(3):197-206.

Muneer, T., N. Abodahab, and A. Gilchrist. 1997. Combined conduction, convection, and radiation heat transfer model for double-glazed windows. Building Services Engineering Research and Technology 18(4):183-91.

Novoselac, A. 2005. Combined airflow and energy simulation program for building mechanical design. $\mathrm{PhD}$ thesis, Department of Architectural Engineering, The Pennsylvania State University, University Park, PN.

Novoselac, A., J.B. Burley, and J. Srebric. 2006a. New convection correlations for cooled ceiling panels in room with mixed and stratified airflow. International Journal of HVAC\&R Research 12(2):281-94.

Novoselac, A., J.B. Burley, and J. Srebric. 2006b. Development of new and validation of existing convection correlations for rooms with displacement ventilation systems. Energy and Buildings 38(3):163-73.

Oosthuizen, P.H. 2008. Three-dimensional effects on convective heat transfer from a window/plane blind system. Heat Transfer Engineering 29(6):565-71.

Pavlovic, M.D. and F. Penot. 1991. Experiments in the mixed convection regime in an isothermal open cubic cavity. Experimental Thermal and Fluid Science 4:648-55.

Spitler, J.D., C.O. Pedersen, D.E. Fisher, P.F. Menne, and J. Cantillo. 1991a. An experimental facility for investigation of indoor convective heat transfer. ASHRAE Transactions 97(1):497-504.

Spitler, J.D., C.O. Pedersen, and D.E. Fisher. 1991b. Interior convective heat transfer in buildings with large ventilative flow rates. ASHRAE Transactions 97(1):505-515.

Wright, J.L., R.C. Michael, and A.K. Nathan. 2009. Improving cooling load calculations for fenestration with shading devices. ASHRAE 1311 RP Report, American Society of Heating, Refrigerating and Air Conditioning Engineers, Inc., Atlanta. 
(c) 2010 American Society of Heating, Refrigerating and Air-Conditioning Engineers, Inc. (www.ashrae.org).

Published in HVAC\&R Research (Vol. 16, Issue 5, September 2010). For personal use only. Additional reproduction, distribution, or transmission in either print or digital form is not permitted without ASHRAE's prior written permission. 